\title{
Out-of-Pile Testing of Radiation Hard Optical Fibers
}

Boise State University:

Sohel Rana, Harish Subbaranman, Nirmala Kandadai Idaho National Laboratory: Kelly McCary, Austin Fleming, Joshua Daw

July 2019

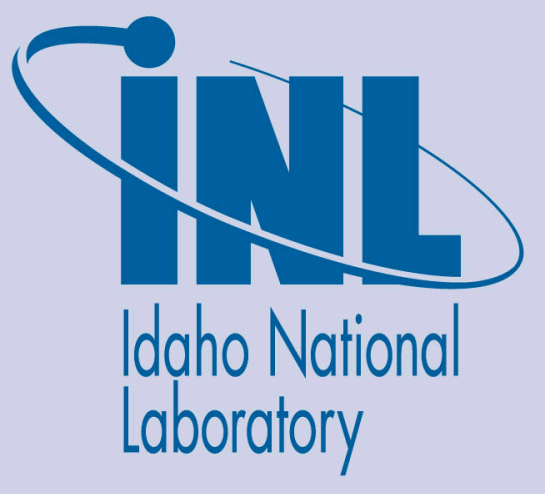




\section{DISCLAIMER}

This information was prepared as an account of work sponsored by an agency of the U.S. Government. Neither the U.S. Government nor any agency thereof, nor any of their employees, makes any warranty, expressed or implied, or assumes any legal liability or responsibility for the accuracy, completeness, or usefulness, of any information, apparatus, product, or process disclosed, or represents that its use would not infringe privately owned rights. References herein to any specific commercial product, process, or service by trade name, trade mark, manufacturer, or otherwise, does not necessarily constitute or imply its endorsement, recommendation, or favoring by the U.S. Government or any agency thereof. The views and opinions of authors expressed herein do not necessarily state or reflect those of the U.S. Government or any agency theof. 


\title{
Out-of-Pile Testing of Radiation Hard Optical Fibers
}

\author{
Boise State University: \\ Sohel Rana, Harish Subbaraman, Nirmala Kandadai \\ Idaho National Laboratory: \\ Kelly McCary, Austin Fleming, Joshua Daw
}

July 2019

Idaho National Laboratory

Idaho Falls, Idaho 83415

http://www.inl.gov

Prepared for the

U.S. Department of Energy

Office of

Under DOE Idaho Operations Office

Contract DE-AC07-05ID14517 
Originating Organization [optional]

\section{Out-of-Pile Testing of Radiation Hard Optical Fibers}

INL/EXT-19-54700

Revision X [only after initial release]

July 2019

Approved by:

Name

Title [optional]

Name

Title [optional]

Name

Title [optional]

Name

Title [optional]
Date

Date

Date

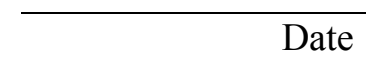

Date 



\begin{abstract}
The work detailed in this report was supported under the In-Pile Instrumentation program for FY19. The work was conducted by researchers at Boise State University (BSU) and Idaho National Laboratory (INL). This report describes the out-of-pile testing that has been conducted to help guide sensor design and data interpretation by providing a robust understanding of out-of-pile fiber optic performance under different environmental factors. Highlighted in this report are two test configurations, transmission testing of optical fibers over a range of temperatures, and tensile testing of optical fibers identified through prior research as having potential for in-core use. The transmission temperature testing is conducted with high spectral resolution to study the influence of elevated temperatures on transmission. This testing has been conducted from room temperature up to $800^{\circ} \mathrm{C}$. The transmission testing was conducted by BSU at the Fiber Laser and Integrated photonics Research (FLaIR) laboratory. This testing will allow separation of radiation and temperature effects during in-core testing and allow for a more thorough understanding of radiation effects on fiber sensors. The tensile testing of optical fibers was conducted to provide a baseline for the strength of fiber optics. The fragile nature of glass fibers is a limitation in the deployment of fiber optics. Furthermore, intrinsic fiber optic sensors such as Fiber Bragg Gratings (FBG) add defects or damaged areas to the fiber which reduce its strength and can lead to broken sensors if not handled with care. The thermo-mechanical test facility enables the ability to quantitatively measure the strength of fibers with and without FBG's over a temperature range. This information will be used to determine which types of FBG's, and other sensors, are likely to survive the installation process. These tests will also be used to characterize the potential measurement range of fiber based strain sensors. The tensile testing was completed at INL in the HTTL Fiber Optics and Ultrasonic Technologies (FOUT) laboratory. Pure silica core (PSC) optical fibers have been shown to perform well in harsh environments. Transmission testing and tensile testing showed little change in fiber dynamic strength and transmission with elevated temperatures. There was no significant weakening of the fiber for temperatures up to $200^{\circ} \mathrm{C}$. Transmission at $1550 \mathrm{~nm}$ (a common wavelength used for optical sensors) showed minimal changes up to $800^{\circ} \mathrm{C}$ with some improvement after 12 hours of annealing at $800^{\circ} \mathrm{C}$. This indicates that PSC optical fiber is a good candidate for in-pile testing.
\end{abstract}




\section{CONTENTS}

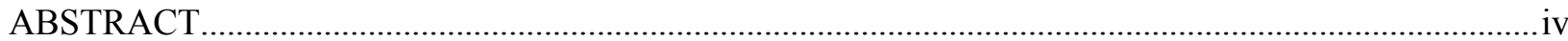

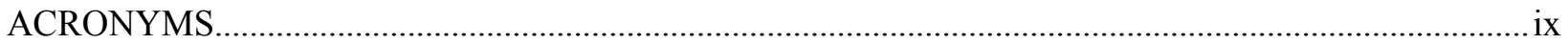

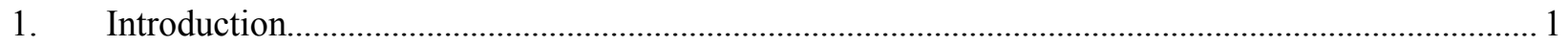

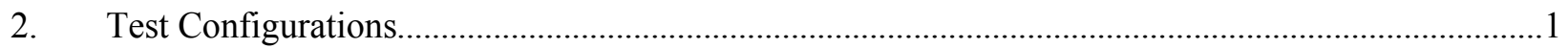

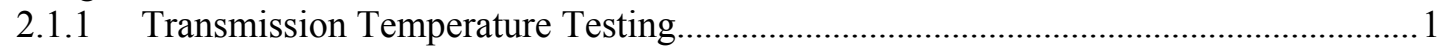

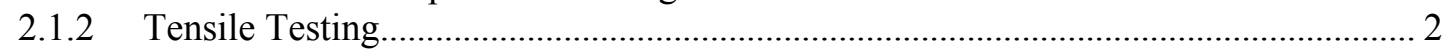

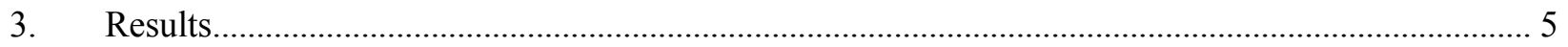

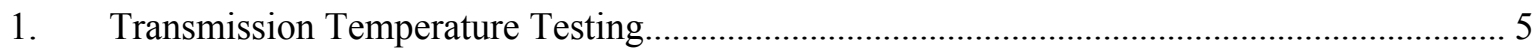

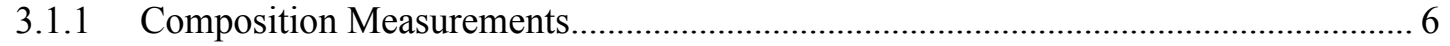

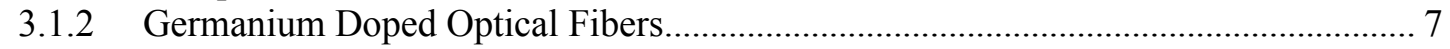

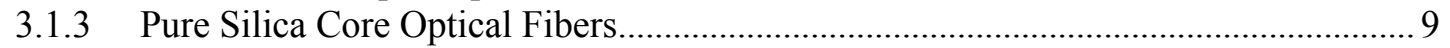

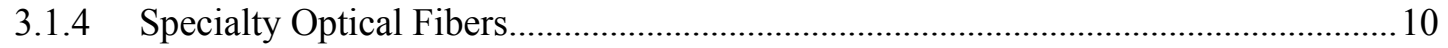

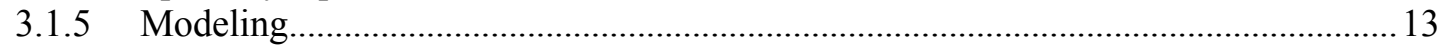

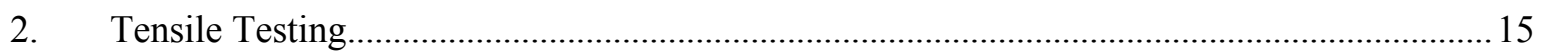

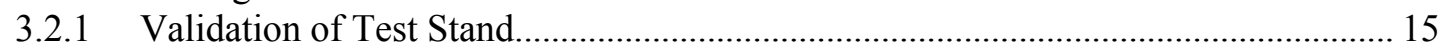

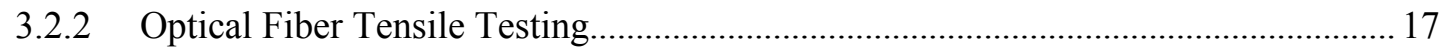

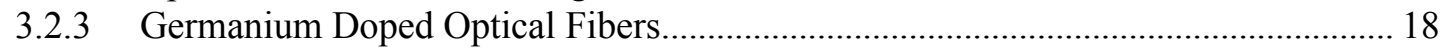

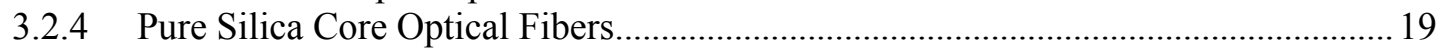

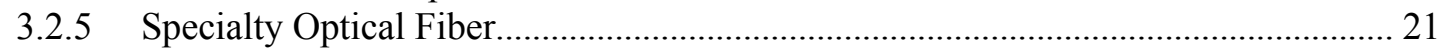

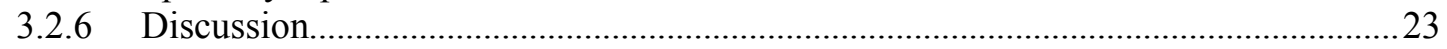

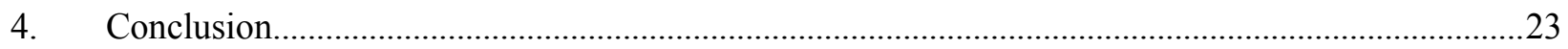

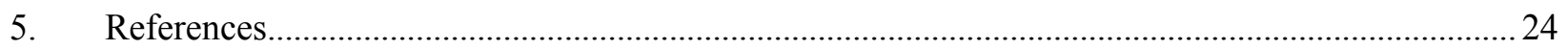

\section{FIGURES}

Figure 1: Experimental set-up for transmission temperature testing of fibers............................................. 2

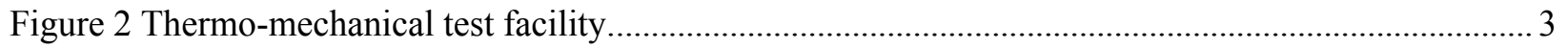

Figure 3: Example of output data from test stand and force gauge...........................................................

Figure 4: EMPA for finding doping concentrations of fibers.......................................................................

Figure 5: Effects of temperature on Ge-doped fiber from Thorlabs and Corning for various

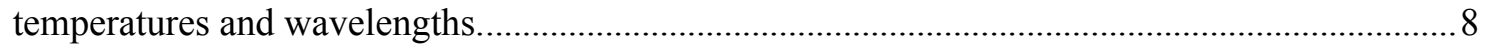

Figure 6: Effects of temperature on F doped fiber from a PSC R-1310 (0.014(GeO2), $0.21(\mathrm{~F}))$

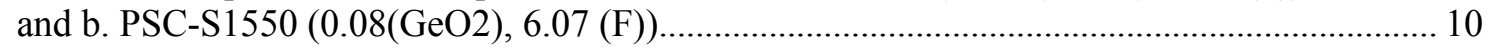

Figure 7: Effects of temperature on the transmission through PSC Polymicro optical fiber....................... 10

Figure 8: Effects of temperature on B-Ge co-doped fiber from Newport at different wavelengths

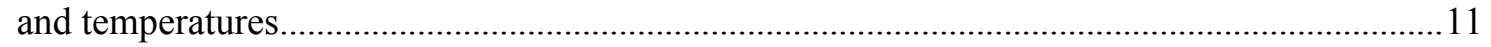

Figure 9: Effects of temperature on Er-doped fiber from Thorlabs............................................................ 12 
Figure 10: Effects of temperature on transmission through Nd-doped fiber from Newport.

Figure 11: Amorphous silica without (left) and with (right) oxygen deficient center (ODC, highlighted by a circle), shown along a axis. Si in dark blue, $\mathrm{O}$ in red.

Figure 12: Optical property comparison between (a \& c) silica with ODC and (b \& d) silica with ODC and $\mathrm{H}$ dopant. .14

Figure 13: Optical properties of silica with ODC and Nd dopant. .14

Figure 14: Optical properties of silica with ODC and B-Ge dopants. 15

Figure 15: Force over travel for 5 samples of stainless steel 304 wire...................................................... 16

Figure 16: Stress vs. strain curves for 5 samples of stainless steel 304 wire........................................... 16

Figure 17: Stress-strain curve for germanium doped clad Corning optical fiber......................................... 18

Figure 18: Stress-strain curve for germanium doped clad Thorlabs optical fiber....................................... 19

Figure 19: Stress-strain curve for pure silica core, fluorine doped clad Nufern 1310 optical fiber.

Figure 20: Stress-strain curve for pure silica core, fluorine doped clad Nufern 1550 optical fiber.

Figure 21: Stress-strain curve for pure silica core, fluorine doped clad Polymicro optical fiber.................20

Figure 22: Stress-strain curve for boron and germanium co-doped optical fiber........................................21

Figure 23: Stress-strain curve for erbium doped optical fibers. Note: The room temperature test

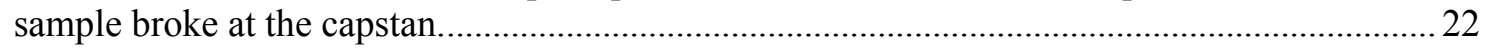

Figure 24: Stress-strain curve for Neodymium and Yttrium doped optical fibers.....................................22

\section{TABLES}

Table 1: Commercially purchased fibers along and the expected radiation response.................................. 5

Table 2: Fibers tested for temperature effects on light transmission........................................................... 6

Table 3: Measured dopant concentration in the cores of the optical fiber samples....................................... 7

Table 4: Summary of dopant effects on irradiated silica........................................................................... 15

Table 5: Experimental modulus of elasticity values from stainless steel 304 wire samples........................ 17

Table 6: Optical fiber samples tested in the thermo-mechanical test facility. (*Fiber fractured at capstan). 


\section{ACRONYMS}

B-Ge - Boron and Germanium co-doped

EPMA - Electron Probe Microanalysis

Er - Erbium

F - Fluorine

FBG - Fiber Bragg Gratings

FLaIR - Fiber Laser and Integrated photonics Research laboratory

FOUT - Fiber Optics and Ultrasonic Technologies laboratory

Ge - Germanium

HTA - High Temperature Acrylate

HTTL - High Temperature Test Laboratory

Nd - Neodymium

ODC - Oxygen Deficient Center

PSC - Pure Silica Core 


\section{Out-of-Pile Testing of Radiation Hard Optical Fibers}

\section{Introduction}

The in-pile conditions sensors must withstand are among the harshest out of any application. The potential combinations of high temperature, high pressure, corrosive environments, and large neutron/gamma fields makes designing and deploying sensors in-pile a difficult problem. Fiber optic sensors have a unique set of complications when it comes to in-pile applications. Specifically, radiation induced compaction, attenuation, and emission can influence sensor performance in addition to other environmental factors. Detailed knowledge of the impact each of these environmental factors has on the sensor performance is required to obtain high confidence of sensor accuracy for in-pile use. The influence these environmental factors have on the measurement will depend on the specific deployment location, the type of fiber optic sensor, and predominately the measurand.

This report describes the out-of-pile testing that has been conducted to help guide sensor design and data interpretation by providing a robust understanding of out-of-pile fiber optic performance under different environmental factors. Highlighted in this report are two test configurations, transmission testing of optical fibers over a range of temperatures, and tensile testing of optical fibers. The transmission temperature testing is conducted with high spectral resolution to study the influence of elevated temperatures on transmission. This testing has been conducted from room temperature up to $800^{\circ} \mathrm{C}$. The tensile testing of optical fibers was conducted to provide a baseline for the strength of fiber optics. The fragile nature of glass fibers is a limitation in the deployment of fiber optics. Furthermore, intrinsic fiber optic sensors such as Fiber Bragg Gratings (FBG) add defects or damaged areas to the fiber which reduce its strength and can lead to broken sensors if not handled with care. The tensile test stand enables the ability to quantitatively measure the strength of fibers with and without FBG's over a temperature range. This information will be used to determine which types of FBG's, and other sensors, are likely to survive the installation process.

\section{Test Configurations}

\subsubsection{Transmission Temperature Testing}

The experimental setup for understanding the effects of temperature on transmission through optical fibers is shown in Figure 1. Most of the fibers had acrylate or polyimide coating that was removed with chemical etching. The temperature tests was performed using Thermolyne furnace with a temperature range up to $1200^{\circ} \mathrm{C}$. The uncoated fiber was inserted into the furnace with the help of a quartz glass tube. One end of the fiber was connected to the laser and the other end was connected to optical spectrum analyzer to measure the transmission through the fiber.

Four types of lasers were used to test the temperature response of different types of fibers at different wavelengths.

(i) ASE 1064 laser (OEQuest)

(ii) 1310 laser (Thorlabs)

(iii) Tunable laser $\mathrm{C}+\mathrm{L}$ bands (Santec)

(iv) ALS laser C+L bands (Amonics)

The input optical power was kept fixed while testing different fibers. 


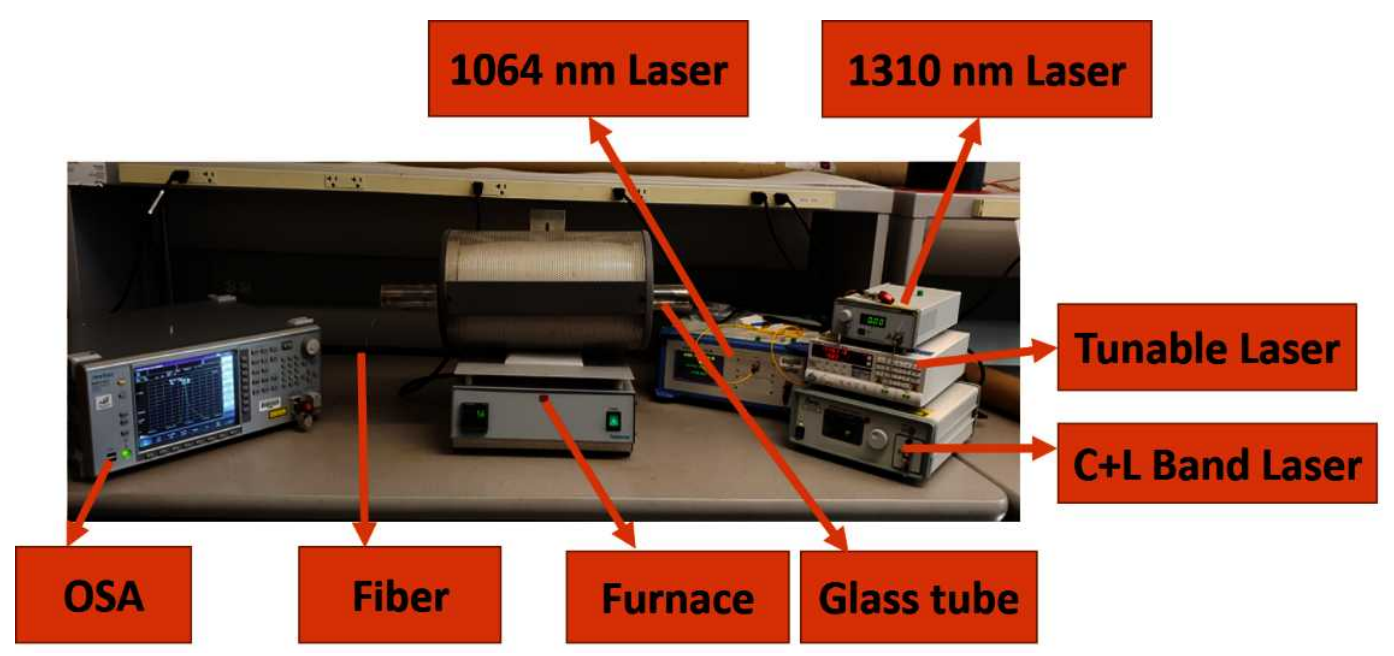

Figure 1: Experimental set-up for transmission temperature testing of fibers.

Temperature was increased from room temperature $\left(25^{\circ} \mathrm{C}\right)$ to $800^{\circ} \mathrm{C}$ with a ramp rate of $3^{\circ} \mathrm{C} / \mathrm{min}$ and data was recorded every $50^{\circ} \mathrm{C}$ interval. The fiber was kept at $800^{\circ} \mathrm{C}$ for 12 hours to understand the annealing effects on fibers.

\subsubsection{Tensile Testing}

A thermo-mechanical test facility was designed and fabricated to test the tensile strength of optical fibers. The facility consists of a motorized tension test stand, two digital force gauges with different resolutions and maximum measurable applied force, and a vertically mounted tube furnace. The motorized test stand is a Mark-10 ESM303 vertical test stand that can be used for tension and compression measurements up to $1.5 \mathrm{kN}$ of force. The thermo-mechanical test facility allows for testing of specimen under tension or compression at temperatures from room temperature up to $1200^{\circ} \mathrm{C}$. Two interchangeable force gauges were procured to measure the applied force on the fiber under tension. Both gauges are Mark-10 series 7 gauges with different maximum applied forces. Figure 2 shows the thermomechanical test facility. 


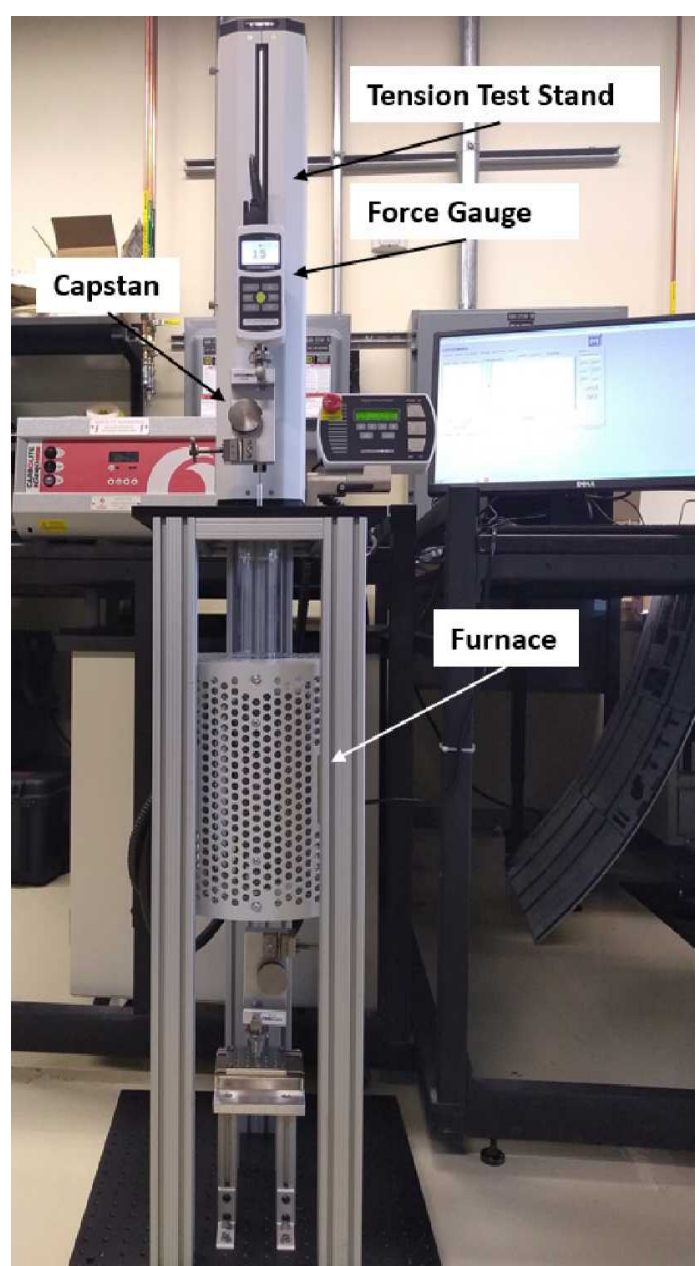

Figure 2 Thermo-mechanical test facility.

The Mark-10 ESM303 vertical test stand can be controlled through a panel attached to the stand or programmed through a pc. The grips used to hold a sample can be easily changed to allow for testing of a wide variety of samples beyond fiber optic test samples. The force gauges allow for a wide range of applied force testing. The first gauge is a model M7-10, this gauge has a maximum force capacity of $50 \mathrm{~N}$ with a resolution of $0.01 \mathrm{~N}$. This gauge is ideal for lower force applications including tension testing thin wires or uncoated optical fibers. The lower maximum applied force allows for higher resolution in the measurement. The second gauge is a model M7-500 with a maximum applied force of $2.5 \mathrm{kN}$ and a resolution of $0.5 \mathrm{~N}$. This gauge is ideal for larger diameter fibers with the coating on the fiber intact or potentially other metal sheathed instrumentation, such as thermocouples. Both of the force gauges sample data at rates up to $14,000 \mathrm{~Hz}$ for fast break scenarios as well as break detection. The furnace in the test facility is a Carbolite Gero tube furnace with a maximum temperature of $1200^{\circ} \mathrm{C}$ and a $150 \mathrm{~mm}$ long heated region. The furnace is best for steady stead testing but can be ramped at a rate up to $5^{\circ} \mathrm{C} / \mathrm{min}$. The furnace allows for the testing of sensors under the thermal conditions that might be experienced in an experiment.

The test set-up records force $(\mathrm{N})$ and distance traveled $(\mathrm{mm})$ which can be converted into stress strain curves to evaluate the mechanical performance of a test sample. Figure 3 shows an example of the data output from the test set-up using stainless steel wire. The thermo-mechanical test facility allows for tension or compression testing of specimens under loads up to $1500 \mathrm{~N}$ from room temperature up to $1200^{\circ} \mathrm{C}$. 


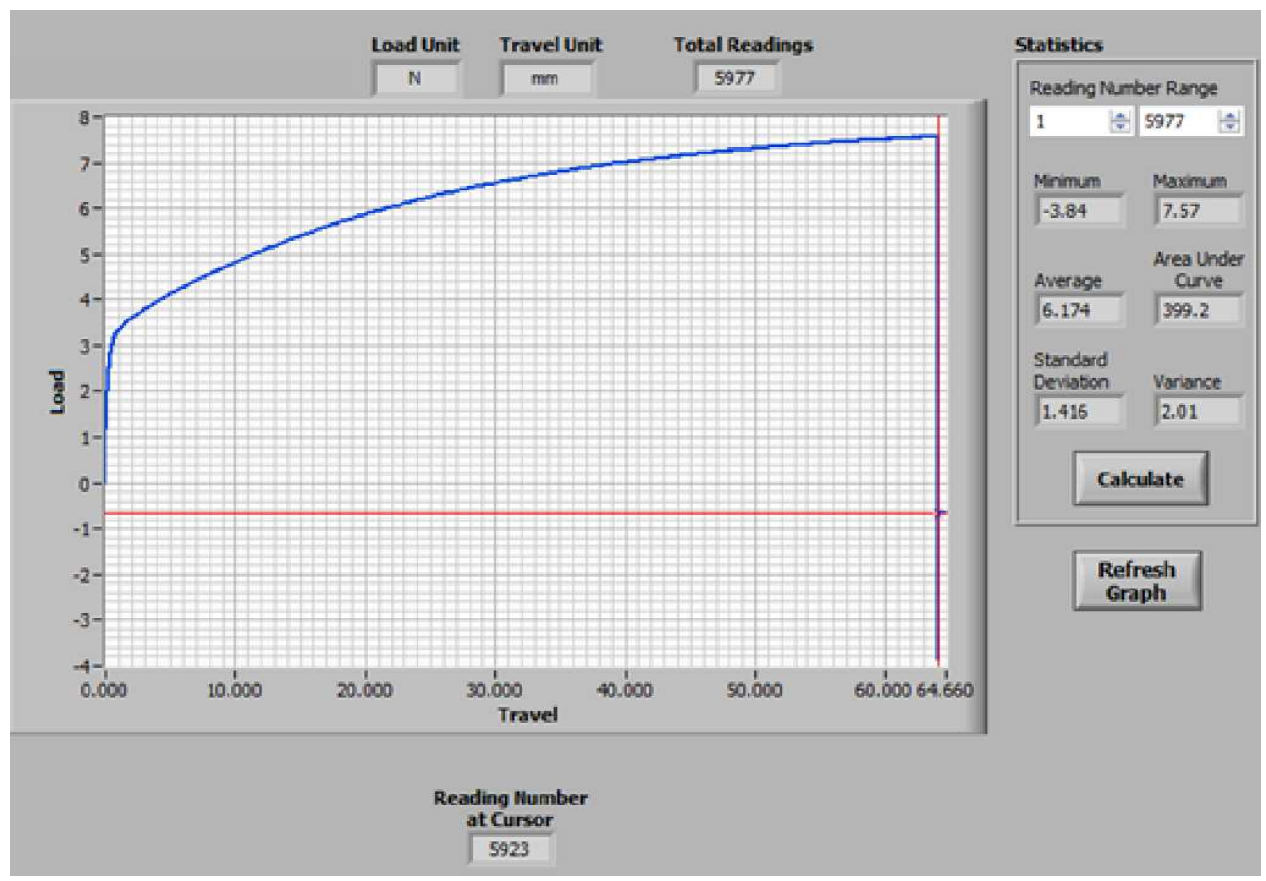

Figure 3: Example of output data from test stand and force gauge.

The apparatus was designed using TIA-455-28-C as guidance, not all of the specifications apply as this facility is designed for small sample sizes for research purposes and not for commercial fiber qualification [1]. The fibers are held on either side by a capstan that was sheathed in an elastomeric, as specified in the standard, to prevent the fiber from slipping. The minimum capstan diameter is specified as $50 \mathrm{~mm}$ to reduce bend stress and fiber breakage at the capstan. Due to the availability of capstans compatible with the tension test stand, the thermo-mechanical test facility is limited to a capstan diameter of $44.5 \mathrm{~mm}$. Throughout the testing only one sample broke at the capstan indicating that the stresses at the capstan are low enough, the data from the sample that broke at the capstan is considered unreliable. The minimum gauge length of the test sample is specified as $500 \mathrm{~mm}$, the gauge length for this test apparatus is $927 \mathrm{~mm}$. There are several accepted methods for stretching the optical fiber sample to failure, the method used in this work was to increase the separation between the gripping capstans at a fixed rate of speed. For dynamic strength measurements the nominal strain rate should be $2.5 \%$ to $5 \%$ increase in length per minute, relative to the gauge length. The nominal strain rate for the testing completed here was $3 \%$ with a separation rate of $28 \mathrm{~mm} / \mathrm{min}$.

In addition to testing the dynamic strength of optical fibers the thermo-mechanical test facility can be used to test a variety of sensors, both optical sensors and others. The current capstans allows for one or both ends of the test sample to extend past the grips for in-situ interrogation of the fiber. This will allow for testing of transmission through the fibers under strain and temperature as well as separate and combined effects testing of sensors. One particularly useful application is testing strain sensors in the furnace to develop methods for distinguishing strain effects from temperature effects. Some optical fiber instrumentation deployments require a fusion splice of the optical fiber. Proof testing the splice for strength and quality will ensure that sensors deployed in experiments survive insertion into the reactor and the duration of the test. The grips on the tension and compression stand can be changed for multiple different types of grips and adapters. Using the compression feature of the facility can allow for bend testing of sensors and cabling, including bend testing of advanced thermocouples under various temperatures. 


\section{Results}

\section{Transmission Temperature Testing}

Optical fiber samples for transmission temperature testing were procured from commercially available sources. A list of the optical fibers used in this testing is listed in Table 1 along with the expected radiation response of each fiber. The fibers were chosen due to their better performance in harsh environments based on a previously completed literature review as well standard telecommunication fibers and specialty fibers.

Table 1: Commercially purchased fibers along and the expected radiation response.

\begin{tabular}{|c|c|c|c|}
\hline Fiber & Parts number & Company & Radiation Response \\
\hline F-doped & FIA200220500 & Polymicro & $\begin{array}{l}\text { Wavelength: } 850 \mathrm{~nm}[2] \\
\text { Dose rate: } 11.4 \mathrm{krad} / \mathrm{min} \\
\text { Total dose: } 1 \mathrm{Mrad} \\
\text { Temperature: } 25^{\circ} \mathrm{C} \\
\text { Loss: } 18 \mathrm{~dB} / \mathrm{km}\end{array}$ \\
\hline Ge-doped & SM28ULTRA & Corning & $\begin{array}{l}\text { Wavelength: } 1310 \mathrm{~nm}[3] \\
\text { Dose rate: } 333 \mathrm{rad} / \mathrm{min} \\
\text { Total dose: } 13.2 \mathrm{Mrad} \\
\text { Temperature: } 25^{\circ} \mathrm{C} \\
\text { Loss: } 47 \mathrm{~dB} / \mathrm{km}\end{array}$ \\
\hline Er-doped & M5-980-125 & Thorlabs & $\begin{array}{l}\text { Wavelength: } 980 \& 1530 \mathrm{~nm}[2,3,4] \\
\text { Total dose: } 2.4 \mathrm{krad} \\
\text { Loss: } 12 \& 7 \mathrm{~dB} / \mathrm{m} \\
\text { Has shown radiation hardness for space applications. }\end{array}$ \\
\hline Yt-doped & $\begin{array}{l}\text { F-YDC-1100- } \\
8 / 230\end{array}$ & Newport & $\begin{array}{l}\text { Yt-doped has shown radiation resistivity at a dose of } \\
2.3 \text { krad at wavelength from } 1000-1600 \mathrm{~nm} \text { only with } \\
8 \% \text { loss of transmission. [5] }\end{array}$ \\
\hline B-Ge-doped & F-SBG-13/15 & Newport & Has shown some radiation hardness.[6] \\
\hline Nd-doped & F-DF1000 & Newport & $\mathrm{N} / \mathrm{A}$ \\
\hline Ge-doped & $1550 \mathrm{BHP}$ & Thorlabs & $\begin{array}{l}\text { Ge-doped has shown radiation resistivity at a dose of } \\
\text { 13.2 Mrad at } 1310 \mathrm{~nm} \text {.[3] }\end{array}$ \\
\hline F-doped & $\mathrm{N} / \mathrm{A}$ & Fiberguide & $\begin{array}{l}\text { F-doped has shown radiation resistivity at a dose of } 1 \\
\text { Mrad at } 850 \mathrm{~nm} \text {. }\end{array}$ \\
\hline Ge-doped & $\mathrm{N} / \mathrm{A}$ & Fiberguide & $\begin{array}{l}\text { Ge-doped has shown radiation resistivity at a dose of } \\
\text { 13.2 Mrad at } 1310 \mathrm{~nm} .[3]\end{array}$ \\
\hline $\begin{array}{l}\text { F-doped } \\
\text { (1310 HTA) }\end{array}$ & R1310-HTA & Nufern & $\begin{array}{l}\text { Pure silica core fiber showed radiation hardness up to } \\
13 \mathrm{MGy} \text { at } 660 \mathrm{~nm}[7,8,9] \\
\text { The silica optical fiber doped with F has shown very } \\
\text { strong radiation resistant characteristics particularly } \\
\text { under the steady state gamma ray ( } \gamma \text {-ray) irradiation } \\
\text { condition. }\end{array}$ \\
\hline $\begin{array}{l}\text { F-doped } \\
\text { (1550 HTA) }\end{array}$ & R1550-HTA & Nufern & $\begin{array}{l}\text { Pure silica core fiber showed radiation hardness up to } \\
13 \mathrm{MGy} \text { at } 660 \mathrm{~nm} \text {. } \\
\text { The silica optical fiber doped with fluorine has } \\
\text { shown very strong radiation resistant characteristics } \\
\text { particularly under the steady state gamma ray ( } \gamma \text {-ray) } \\
\text { irradiation. }\end{array}$ \\
\hline
\end{tabular}




\begin{tabular}{|l|l|l|}
\hline $\begin{array}{l}\text { Pure silica } \\
\text { FBG }\end{array}$ & Fiberguide & $\begin{array}{l}\text { Femtosecond-etched FBGs have shown substantial } \\
\text { radiation hardness. }\end{array}$ \\
\hline
\end{tabular}

Table 2 lists the fibers that were tested for the effect of temperature on transmission of light through the fiber. One fiber was tested from each sample and transmission data was taken with each of the lasers at each temperature step.

Table 2: Fibers tested for temperature effects on light transmission.

\begin{tabular}{|c|c|c|c|}
\hline Core & Cladding & Company & Coating \\
\hline Ge-doped & PSC & Corning & Dual Acrylate \\
\hline Ge-doped & PSC & Thorlabs & Acrylate \\
\hline B-Ge-co-doped & PSC & Newport & Dual Acrylate \\
\hline PSC-R1310 & F-doped & Nufern & Dual Acrylate \\
\hline PSC-S1550 & F-doped & Nufern & Dual Acrylate \\
\hline PSC & F-doped & Polymicro & Acrylate \\
\hline Nd-doped & PSC & Newport & Dual Acrylate \\
\hline Er-doped & PSC & Thorlabs & Acrylate \\
\hline
\end{tabular}

\subsubsection{Composition Measurements}

Electron probe microanalysis (EPMA) was performed to verify the composition of the optical fiber samples. The procedure to test a fiber for EPMA is given below and is schematically shown in Figure 4.

(i) Cleave optical fibers into 1 inch samples

(ii) Place fiber samples in epoxy resin and cure

(iii) Polish the fiber samples mechanically with $\mathrm{SiC}$ and then magnetic plates

(iv) Diamond lap the surface to ensure the fiber surface is flat

(v) Mount polished samples for EMPA.

The measured dopant concentrations in the cores of the optical fiber samples is given in Table 3 .

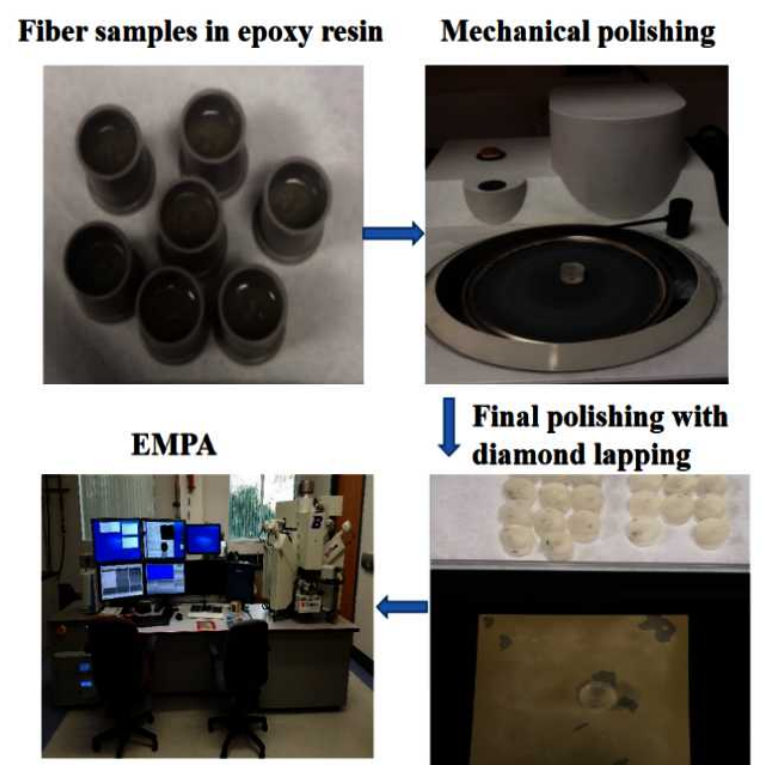


Figure 4: EMPA for finding doping concentrations of fibers.

Table 3: Measured dopant concentration in the cores of the optical fiber samples.

\begin{tabular}{|c|c|c|c|}
\hline Core & Cladding & Company & Core dopants (\%) \\
\hline Ge-doped & PSC & Corning & $0.13\left(\mathrm{GeO}_{2}\right)$ \\
\hline Ge-doped & PSC & Thorlabs & $0.27\left(\mathrm{GeO}_{2}\right)$ \\
\hline B-Ge-co-doped & PSC & Newport & Yet to be measured \\
\hline PSC-R1310 & F-doped & Nufern & $0.014\left(\mathrm{GeO}_{2}\right), 0.21(\mathrm{~F})$ \\
\hline PSC-S1550 & F-doped & Nufern & $0.08\left(\mathrm{GeO}_{2}\right), 6.07(\mathrm{~F})$ \\
\hline PSC & F-doped & Polymicro & $0.05\left(\mathrm{GeO}_{2}\right), 0.13(\mathrm{~F})$ \\
\hline Nd-doped & PSC & Newport & $0.004\left(\mathrm{Nd}_{2} \mathrm{O}_{3}\right)$ \\
\hline Er-doped & PSC & Thorlabs & Yet to be measured \\
\hline
\end{tabular}

\subsubsection{Germanium Doped Optical Fibers}

Figure 5 shows the transmission characteristics of Ge doped optical fibers with two different dopant concentrations, $0.27 \% \mathrm{Ge}$ in the Thorlabs fiber and $0.17 \%$ in the Corning fiber, for increasing temperatures at various wavelengths. The transmission at $1550 \mathrm{~nm}$ in the lower germanium concentration fiber (Corning) worsens with increases in temperature. Annealing the fiber at $800^{\circ} \mathrm{C}$ improves its transmission. The higher germanium concentration fiber (Thorlabs) has a near stable transmission at 1550 $\mathrm{nm}$ with temperature. The transmission initially decreases up to $300^{\circ} \mathrm{C}$ then increases for temperatures over $300^{\circ} \mathrm{C}$. Transmission at $1064 \mathrm{~nm}$ in both fibers is superior than the transmission at $1550 \mathrm{~nm}$, and the transmission increases upon annealing with temperature. The transmission initially decreases at around $300^{\circ} \mathrm{C}$ and then improves with temperature, with trend reversing again at $600^{\circ} \mathrm{C}$. It should be noted that the center wavelength shifts for the $1550 \mathrm{~nm}$ centered transmission test for both fibers. The shifts are most likely due to changing laser cavity temperature and not attenuation in the optical fiber.
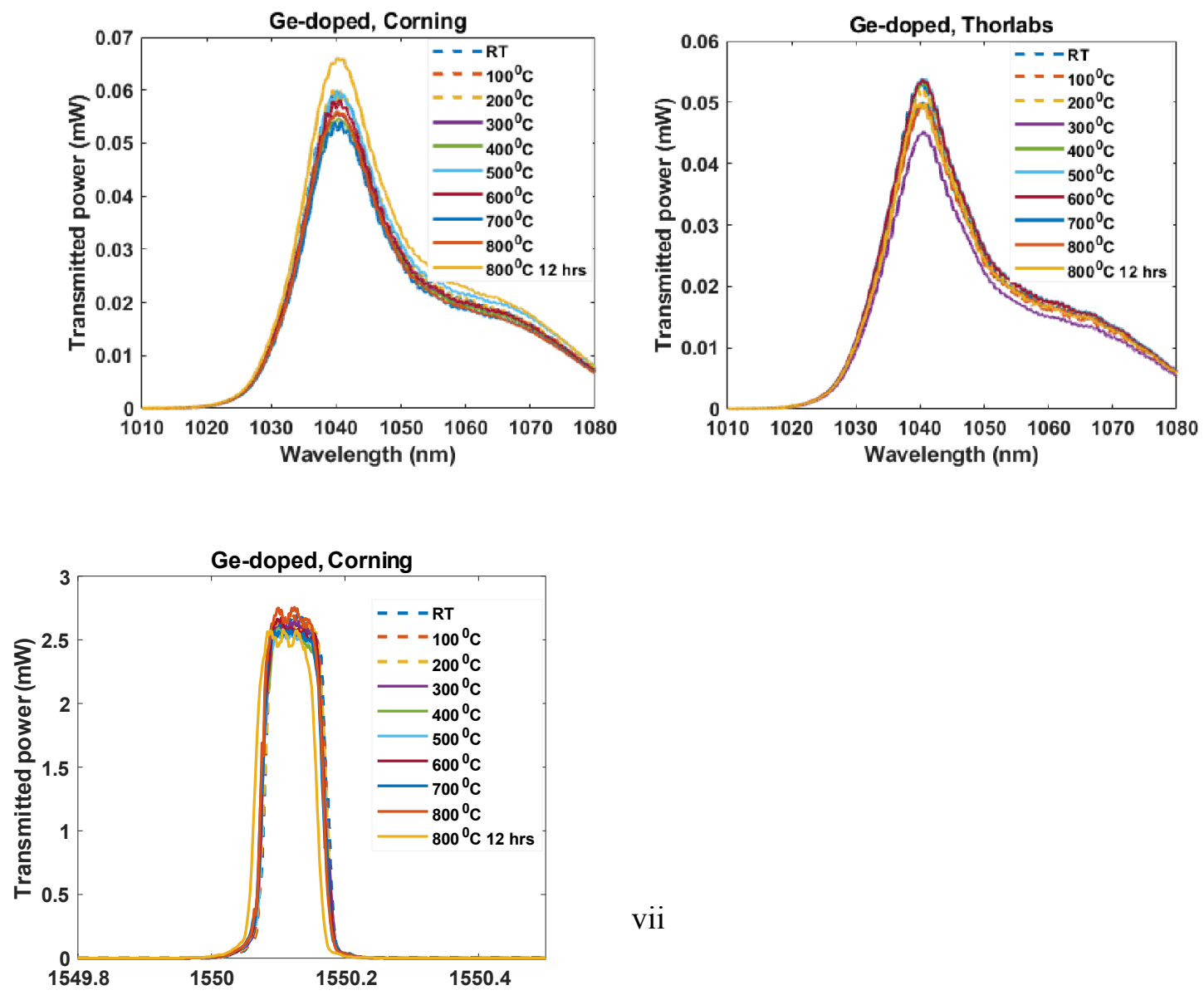

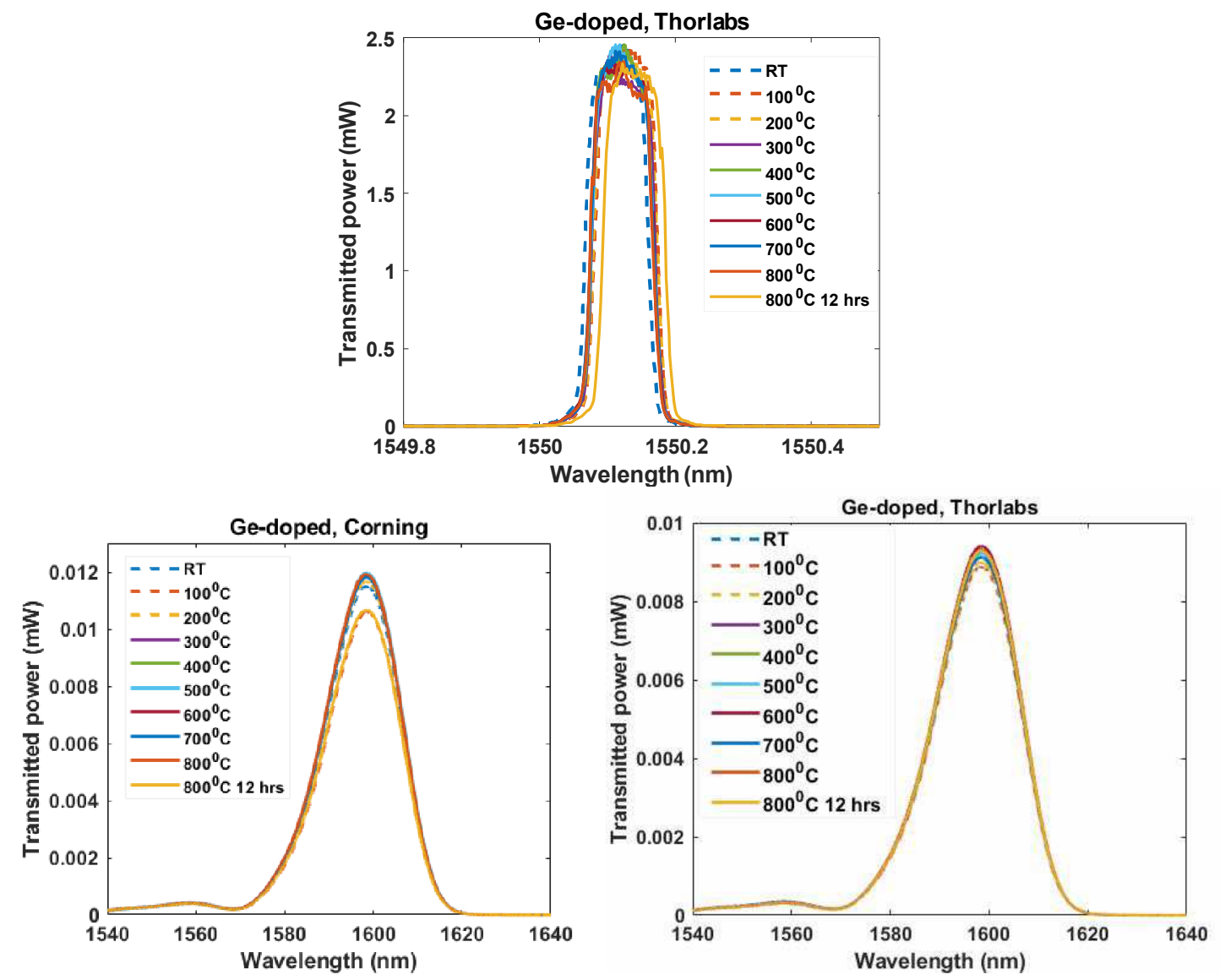

Figure 5: Effects of temperature on Ge-doped fiber from Thorlabs and Corning for various temperatures and wavelengths.

\subsubsection{Pure Silica Core Optical Fibers}

Pure silica core optical fibers have been reported to have good radiation resistance [2, 7-9]. Three types of PSC optical fibers with fluorine doped clad were tested, two fibers from Nufern and one fiber from Polymicro. Although the specifications from Nufern claim that the core dopant is pure silica, the EMPA analysis showed the fiber rated for $1310 \mathrm{~nm}$ has $0.21 \%$ of fluorine and the one rated for $1550 \mathrm{~nm}$ has $6 \%$ fluorine. The fluorine dopant in the fiber clad may have diffused into the fiber cores. For the discussion, we will state that the $1550 \mathrm{~nm}$ fiber has higher fluorine dopant in comparison to $1310 \mathrm{~nm}$ fiber. Figure 6 shows the effects of temperature on the transmission through fluorine-doped silica fiber.

At room temperature and $1550 \mathrm{~nm}$ the transmission through the Nufern 1310 is negligible, this is unsurprising as the fiber is designed to transmit at $1310 \mathrm{~nm}$. As temperature is increased, the transmission spectrum of the Nufern 1310 fiber improves significantly, with the best transmission at $800^{\circ} \mathrm{C}$ after annealing, this is most likely due to clad dopants diffusing into the core of the fiber and broadening the mode field diameter of the fiber thereby allowing the transmission of longer wavelengths. The Nufern 1550 has a fairly stable performance at $1550 \mathrm{~nm}$, the wavelength the fiber was designed for. The shift in center wavelength from the transmission at room temperature compared to transmission at the elevated temperatures is likely due to changing laser cavity temperature and not attenuation in the optical fiber. At $1064 \mathrm{~nm}$, the Nufern 1310 fiber is fairly stable and the transmission improves slightly with increasing temperature. The Nufern 1550 fiber transmission weakens with increasing temperature.

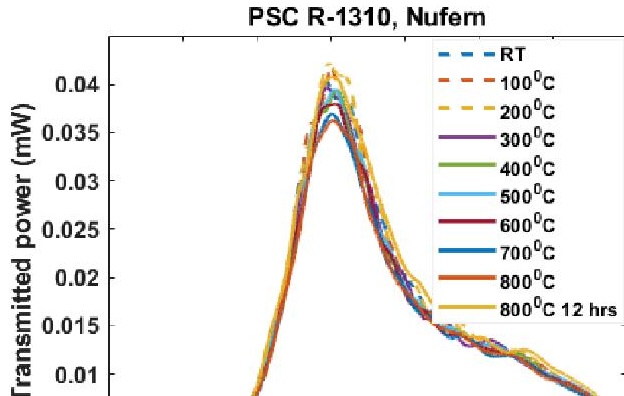



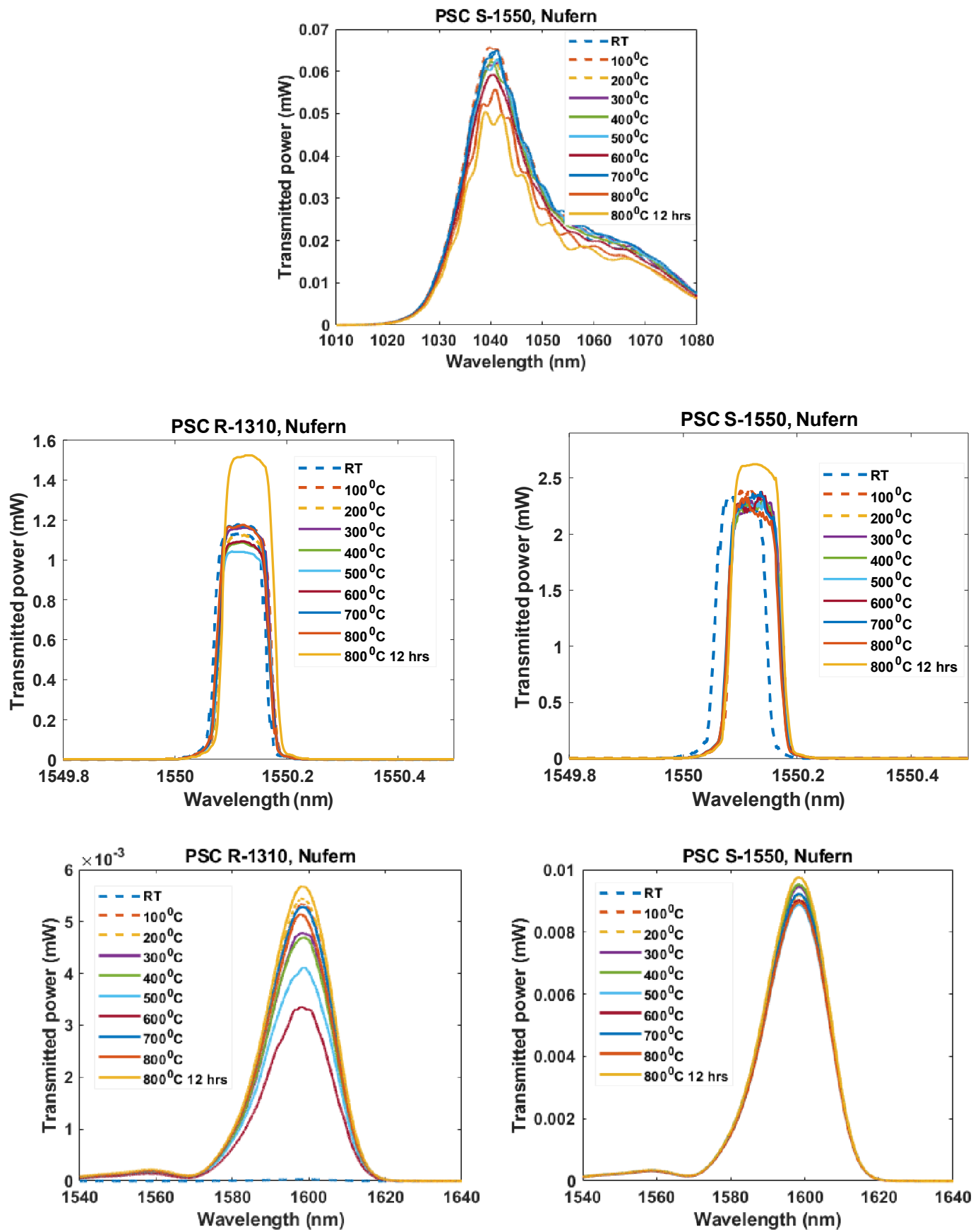

Figure 6: Effects of temperature on F doped fiber from a PSC R-1310 (0.014(GeO2), $0.21(\mathrm{~F}))$ and b. PSC-S1550 (0.08(GeO2), $6.07(\mathrm{~F}))$.

In addition to PSC fluorine doped clad fiber from Nufern, similar fiber from Polymicro was also tested. The transmission results are shown in Figure 7. This fiber has trace amounts of fluorine and germanium with $0.13 \%$ and $0.05 \%$ respectively. This fiber behaved very differently from the other fibers, at $1550 \mathrm{~nm}$ and $1064 \mathrm{~nm}$ the transmission was very noisy. At $1550 \mathrm{~nm}$ and $1064 \mathrm{~nm}$, the best transmission is at room temperature and the transmission significantly worsens with increasing temperature. The transmission in this fiber is poor because the fiber was not designed to operate at these wavelengths. 


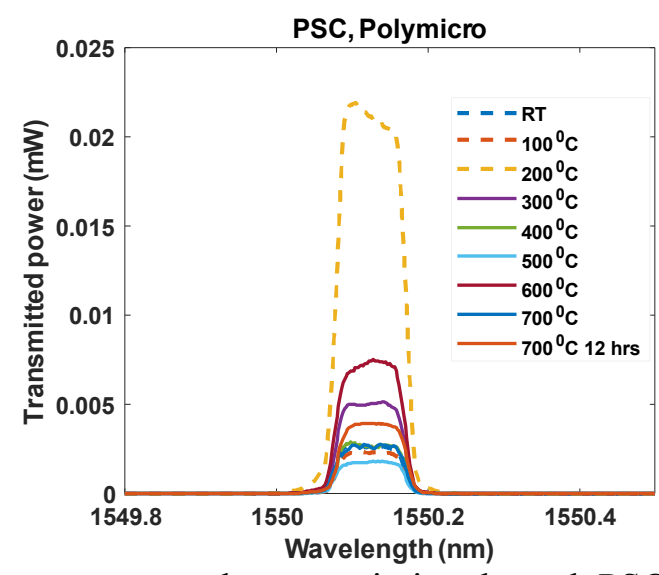

Figure 7: Effects of temperature on the transmission through PSC Polymicro optical fiber.

\subsubsection{Specialty Optical Fibers}

Three specialty fibers were chosen for potential sensor applications rather than just radiation tolerance. A boron and germanium co-doped optical fiber, an erbium doped optical fiber, and a neodymium doped optical fiber were all tested for transmission at various temperatures.

\subsubsection{Boron and Germanium Co-doped Optical Fibers}

This specialty fiber has potential applications as a neutron detection sensor because boron has a high neutron cross section making it very sensitive to neutron flux. Figure 8 shows the transmission through the fiber at $1064 \mathrm{~nm}$, and $1550 \mathrm{~nm}$ for temperatures from room temperature up to $800^{\circ} \mathrm{C}$. The transmission at $1550 \mathrm{~nm}$ decreases with increasing temperature however, annealing improves the transmission at $800^{\circ} \mathrm{C}$. The shift in center wavelength from the transmission at room temperature and $800^{\circ} \mathrm{C}$ compared to transmission at the other temperatures is likely due to changing laser cavity temperature and not attenuation in the optical fiber. The transmission at $1064 \mathrm{~nm}$ is fairly stable with a slight decrease with increasing temperatures.

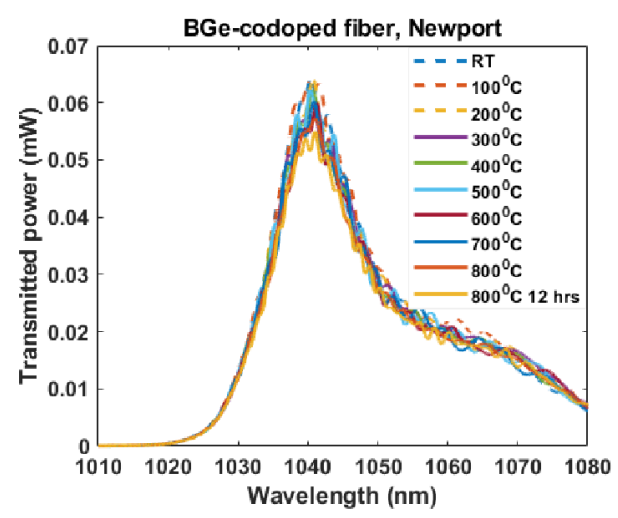



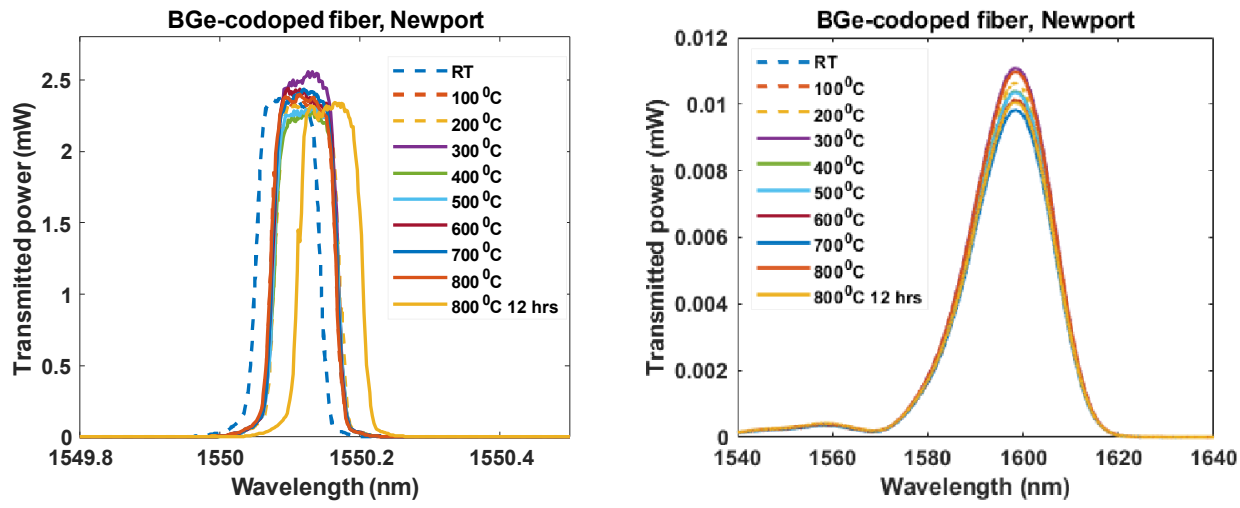

Figure 8: Effects of temperature on B-Ge co-doped fiber from Newport at different wavelengths and temperatures.

\subsubsection{Erbium Doped Optical Fibers}

Erbium doped fibers have not been tested inside a reactor. Figure 9 shows the transmission through the fiber at $1064 \mathrm{nmand} 1550 \mathrm{~nm}$ for temperatures from room temperature up to $800^{\circ} \mathrm{C}$. At $1550 \mathrm{~nm}$ increasing temperature improves signal transmission up to $600^{\circ} \mathrm{C}$. After $600^{\circ} \mathrm{C}$ the transmission power drops with increasing temperature. A shift in center wavelength from the transmission at room temperature compared to transmission at the elevated temperatures is likely due to changing laser cavity temperature and not attenuation in the optical fiber. Annealing at $800^{\circ} \mathrm{C}$ recovers some of the reduced transmission. At $1064 \mathrm{~nm}$ the fiber transmission improves with increasing temperature.
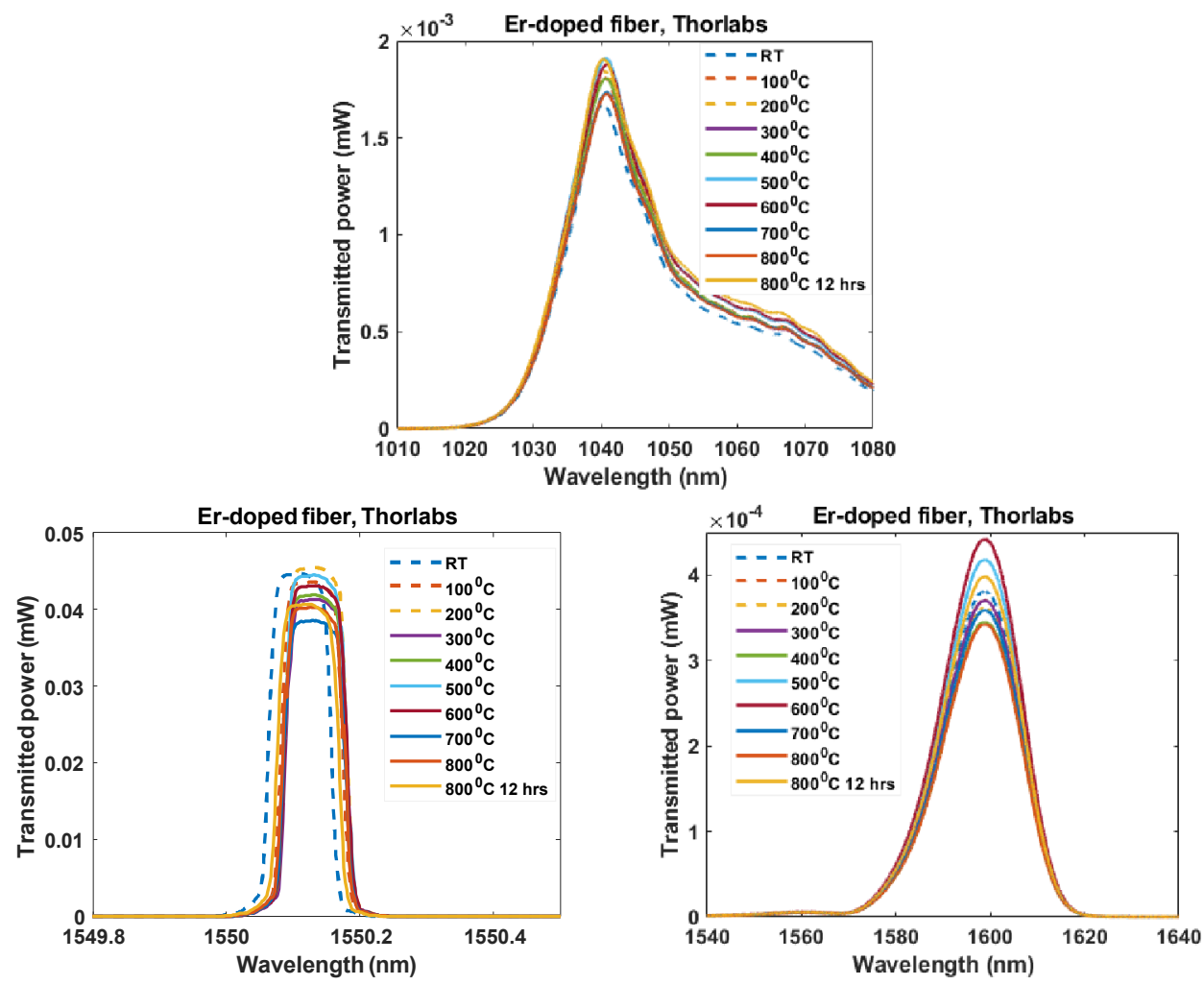

Figure 9: Effects of temperature on Er-doped fiber from Thorlabs. 


\subsubsection{Neodymium Doped Optical Fibers}

Neodymium (Nd) doped fibers are fibers with pure silica core and a Nd doped clad. Figure 10 shows the effect of temperature on transmission through the fiber at different wavelengths. Increasing temperature improves signal transmission at $1550 \mathrm{~nm}$ up to $400^{\circ} \mathrm{C}$, after $400^{\circ} \mathrm{C}$, the transmitted power drops slightly with increasing temperature. Annealing at $800^{\circ} \mathrm{C}$ reduces the transmission power, however the shift in center wavelength from the transmission after annealing at $800^{\circ} \mathrm{C}$, compared to transmission at the other temperatures, is likely due to changing laser cavity temperature and not attenuation in the optical fiber. The fiber transmission improves with increasing temperature at $1064 \mathrm{~nm}$, at $800^{\circ} \mathrm{C}$ the annealing causes some reduction in transmitted power.
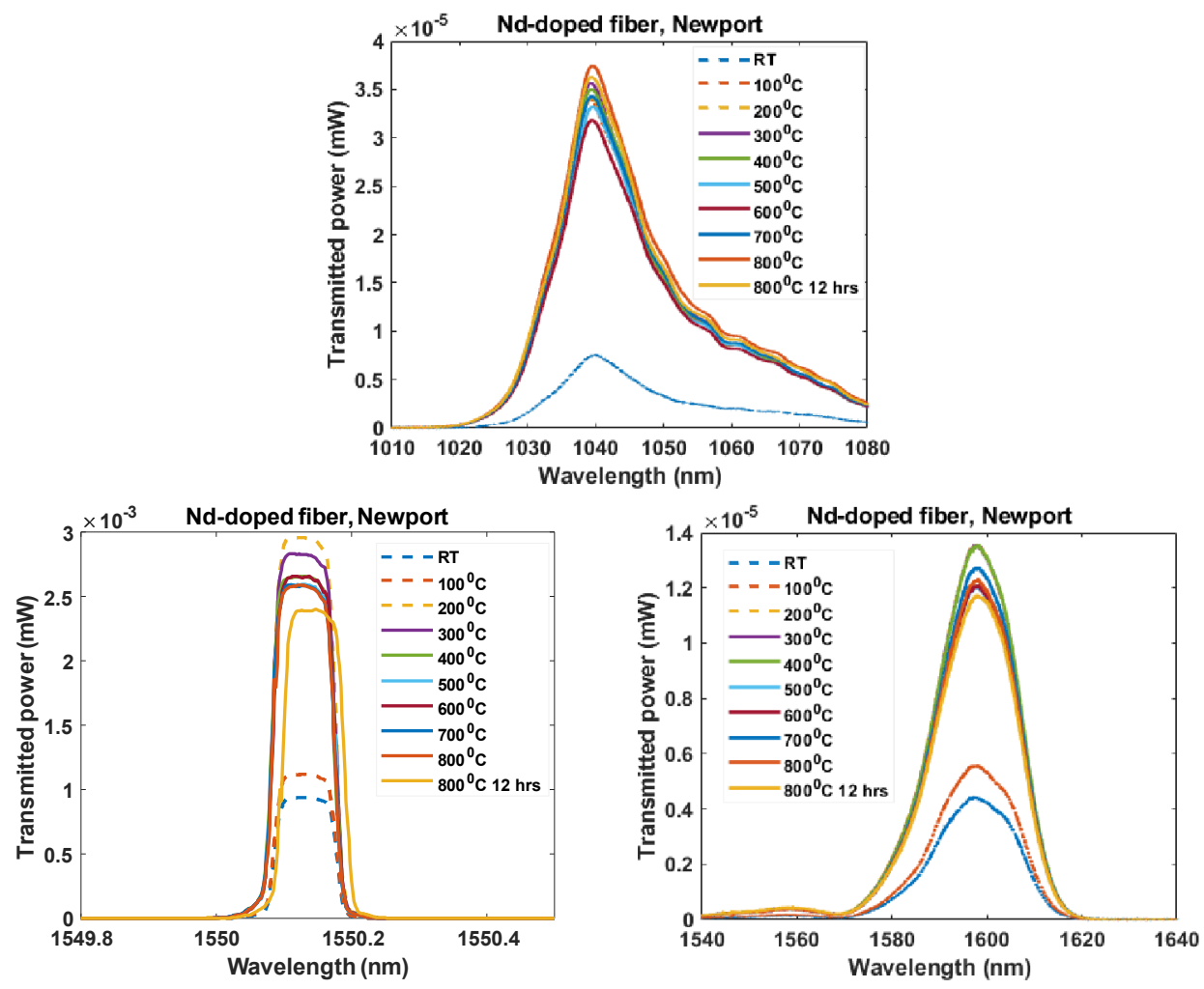

Figure 10: Effects of temperature on transmission through Nd-doped fiber from Newport.

\subsubsection{Modeling}

Based on density functional theory (DFT), Vienna ab initio simulation package (VASP) [10] was performed to calculate atomic and electronic structures, and optical properties. The Perdew-BurkeErnzerhof (PBE) [11] form of the generalized gradient approximation (GGA) was selected to calculate exchange-correlation potential for electron-electron interaction. Plane-wave expansion of the wave function was performed with the projector augmented wave (PAW) method. A cutoff energy of $600 \mathrm{eV}$ was used with a $5 \times 5 \times 5$ gamma centered mesh sampling through Brillouin zone. The structures were fully optimized with residual forces reduced to smaller than $0.01 \mathrm{eV} / \AA$. To predict structural stability at high temperature, we performed ab-initio molecular dynamic simulations (AIMD) by heating the structure to above $2000 \mathrm{~K}$ and then annealing it at $573 \mathrm{~K}$.

To determine the defect and dopant effects, we calculated the refractive index and extinction coefficient 
of silica-based structure. From frequency-dependent dielectric matrix including real and imaginary

parts, refractive index was calculated as below [5-7]:

Extinction coefficient $k$ was given by,

\subsubsection{Discussion}

Figure 11 shows the bulk structure of amorphous silica $\left(\mathrm{a}-\mathrm{SiO}_{2}\right)$ without and with an oxygen deficient center (ODC). This radiation defect in silica has a positive-charge state. The defect center consists of a positively charged oxygen vacancy, where an unpaired electron is shared by two Si atoms
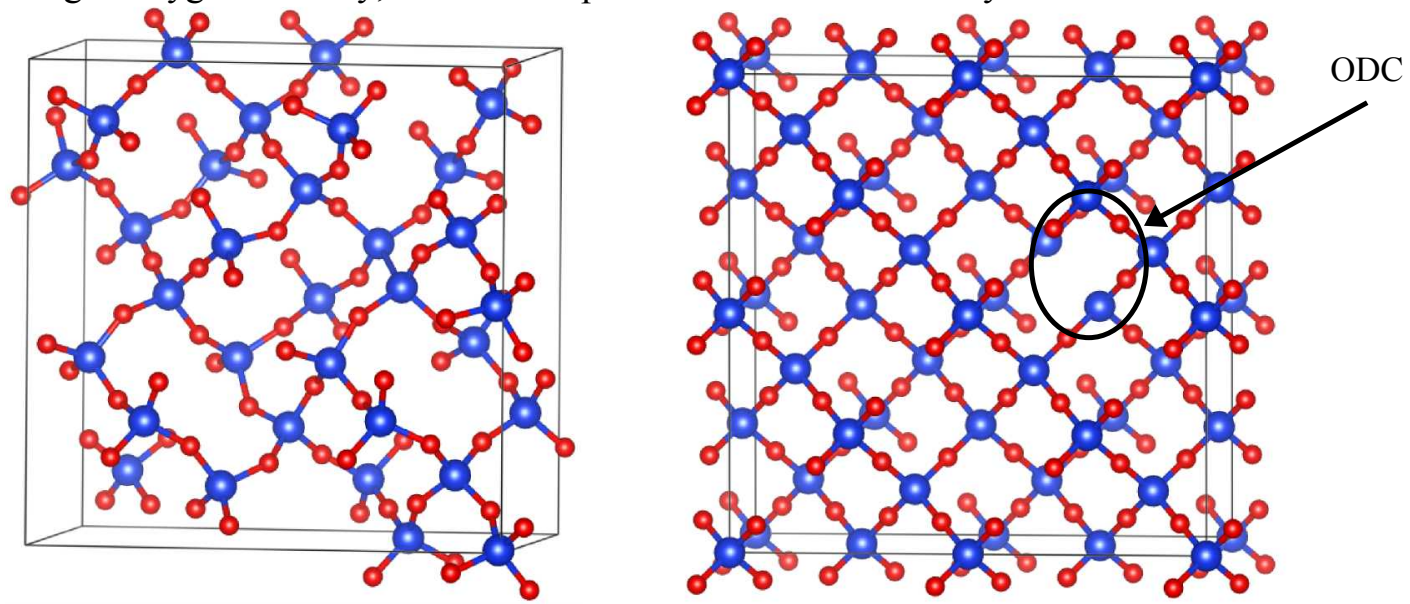

Figure 11: Amorphous silica without (left) and with (right) oxygen deficient center (ODC, highlighted by a circle), shown along a axis. Si in dark blue, $\mathrm{O}$ in red.

Figure 12 shows refractive indices and extinction coefficients for silica with ODC and silica with $\mathrm{ODC}$ and $\mathrm{H}$ dopant for comparison. We found absorption peak at $\sim 6 \mathrm{eV}$ and refractive index of 1.38 in the presence of ODC. Inclusion of $\mathrm{H}$ decreases the magnitude of absorption peak, but refractive index remains the same. Slight anisotropy exists between different light polarization directions. These observations are the consequence of $\mathrm{H}$ diffusion in the silica to replace ODC. 
(a)

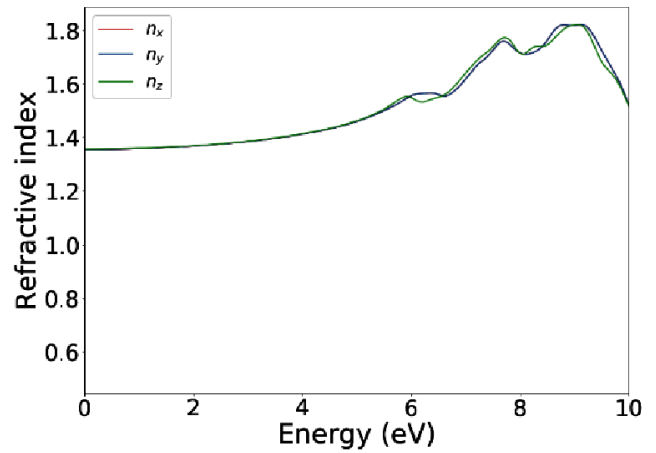

(c)

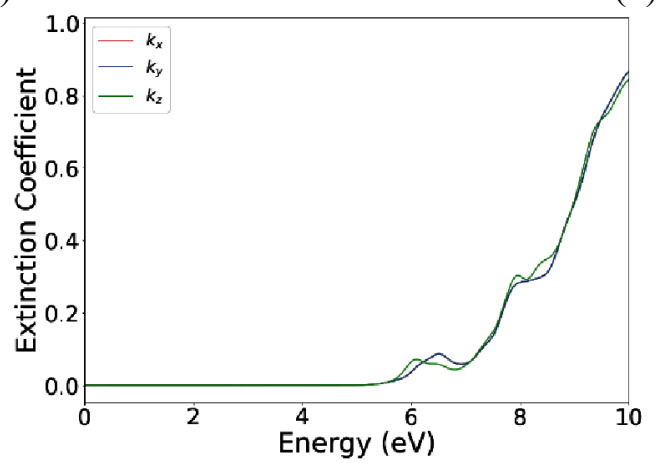

(d) (b)
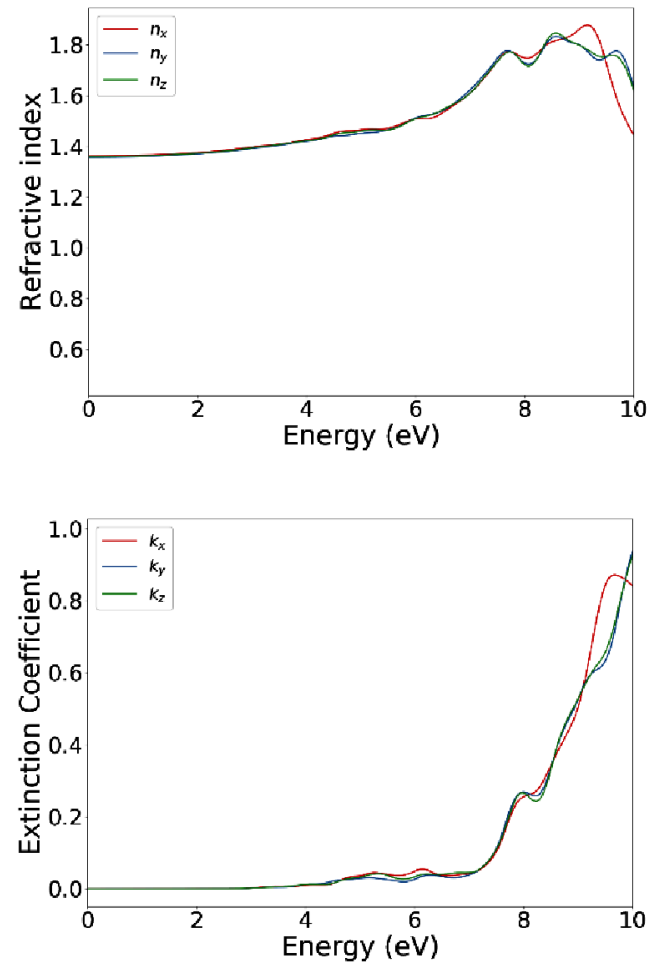

Figure 12: Optical property comparison between (a \& c) silica with ODC and (b \& d) silica with ODC and $\mathrm{H}$ dopant.

Figure 13 shows refractive index and extinction coefficient for silica with ODC and $\mathrm{Nd}$ dopant. $\mathrm{Nd}$ is larger than $\mathrm{H}$. Inclusion of $\mathrm{Nd}$ increases refractive index to 1.5 ( $\mathrm{x}$ and y-polarized) and 1.82 (z-polarized) and induced additional absorption peaks. Large anisotropy exists between different light polarization directions. Due to its large size, Nd dopant cannot diffuse through silica to replace ODC.

(a)

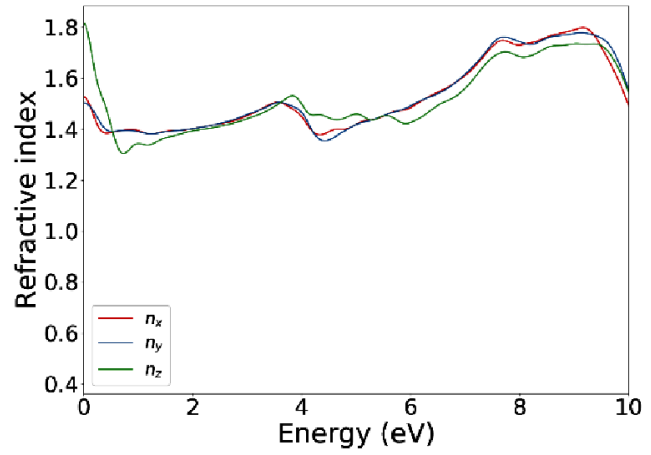

(b)

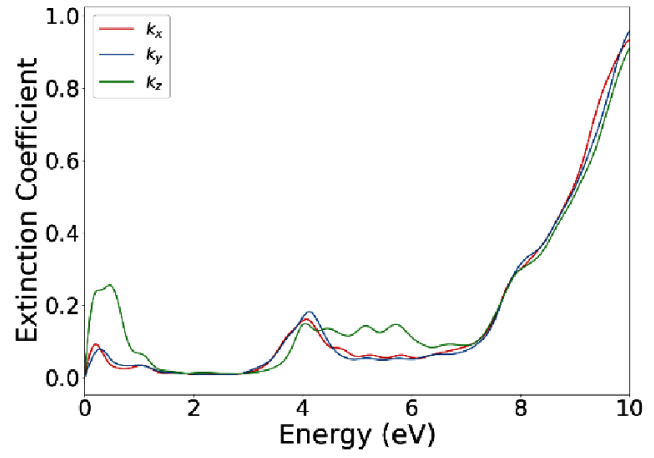

Figure 13: Optical properties of silica with ODC and Nd dopant

Besides individual dopants, we tested co-dopants (i.e. inclusion of two different types of dopants) in the silica. Figure 14 shows refractive index and extinction coefficient for silica with ODC and B-Ge dopants. Inclusion of B-Ge increases static refractive index to just above 1.4 and induces more absorption peaks. Large anisotropy exists between different light polarization directions. Due to their size difference, B 
dopant can diffuse into ODC while Ge dopant remains near B dopant.

(a)

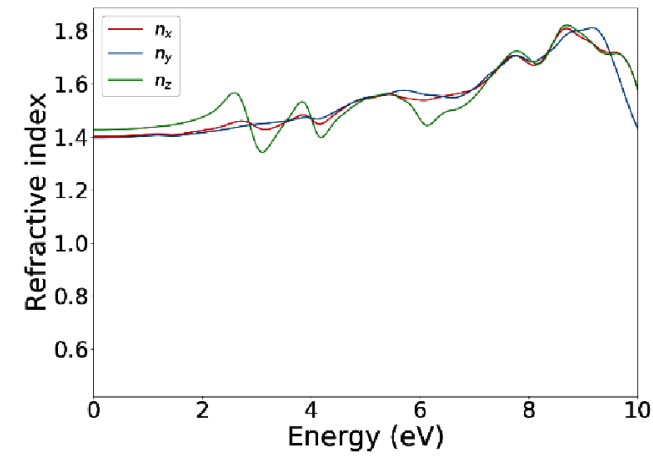

(b)

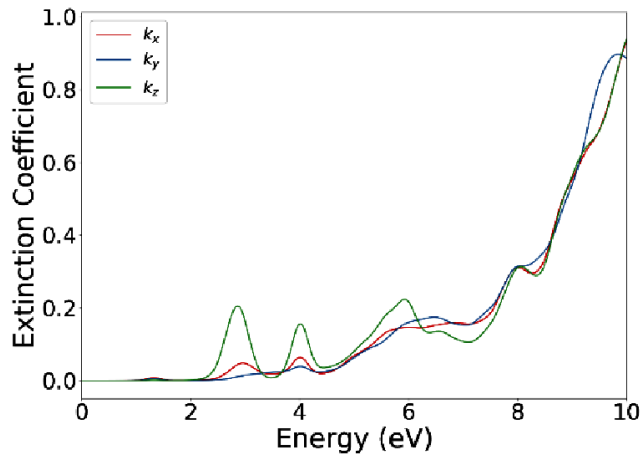

Figure 14: Optical properties of silica with ODC and B-Ge dopants

We tested dopants with different sizes to determine their effects on the structure and optical properties of silica with ODC. Table 4 summarizes the effects. Small dopants can prevent radiation defect formation through replacement. They also improve optical properties of irradiated silica. These computational results help predict radiation effects and ideal compositions for optical fibers.

Table 4: Summary of dopant effects on irradiated silica

\begin{tabular}{|c|c|c|c|}
\hline & $\begin{array}{c}\text { Small Dopant (e.g. } \\
\text { H, F) }\end{array}$ & $\begin{array}{c}\text { Large Dopant (e.g. } \\
\text { Ge, Nd) }\end{array}$ & $\begin{array}{c}\text { Co-Dopant (e.g. O- } \\
\text { H, B-Ge) }\end{array}$ \\
\hline $\begin{array}{c}\text { Additional } \\
\text { Absorption Peaks }\end{array}$ & $\boldsymbol{x}$ & $\checkmark$ & $\checkmark$ \\
\hline "Filled-in" ODC & $\checkmark$ & $\boldsymbol{x}$ & $\checkmark / \mathbf{x}$ \\
\hline $\begin{array}{c}\text { Static refractive } \\
\text { index increase }\end{array}$ & $\mathbf{x}$ & $\checkmark$ & $\checkmark$ \\
\hline
\end{tabular}

\section{Tensile Testing}

\subsubsection{Validation of Test Stand}

To ensure the test set-up is functional and producing reliable data, stainless steel 304 wire was tested. The stainless steel wire was placed in the test stand and evaluated to compare the known modulus of elasticity to the experimentally calculated value using the test stand. Figure 15 shows the force vs. travel data and Figure 16 shows the data from Figure 15 converted to the stress vs. strain curves for 5 samples of the stainless steel wire. 


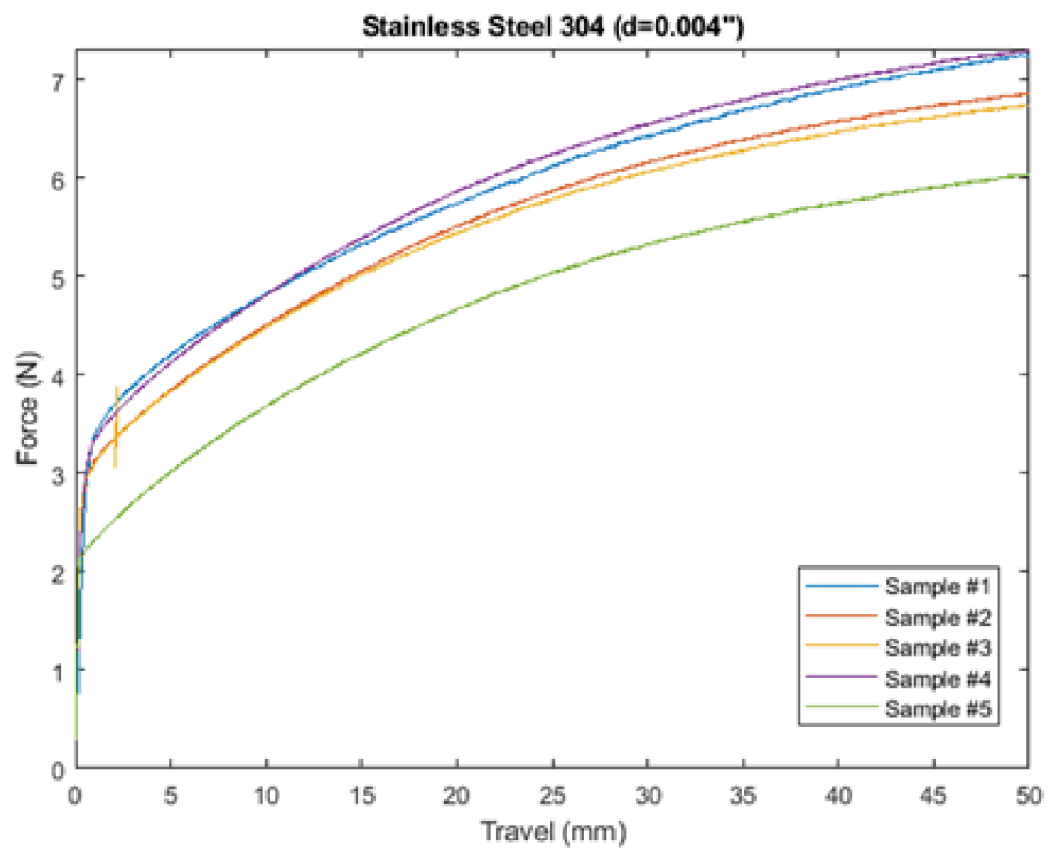

Figure 15: Force over travel for 5 samples of stainless steel 304 wire.

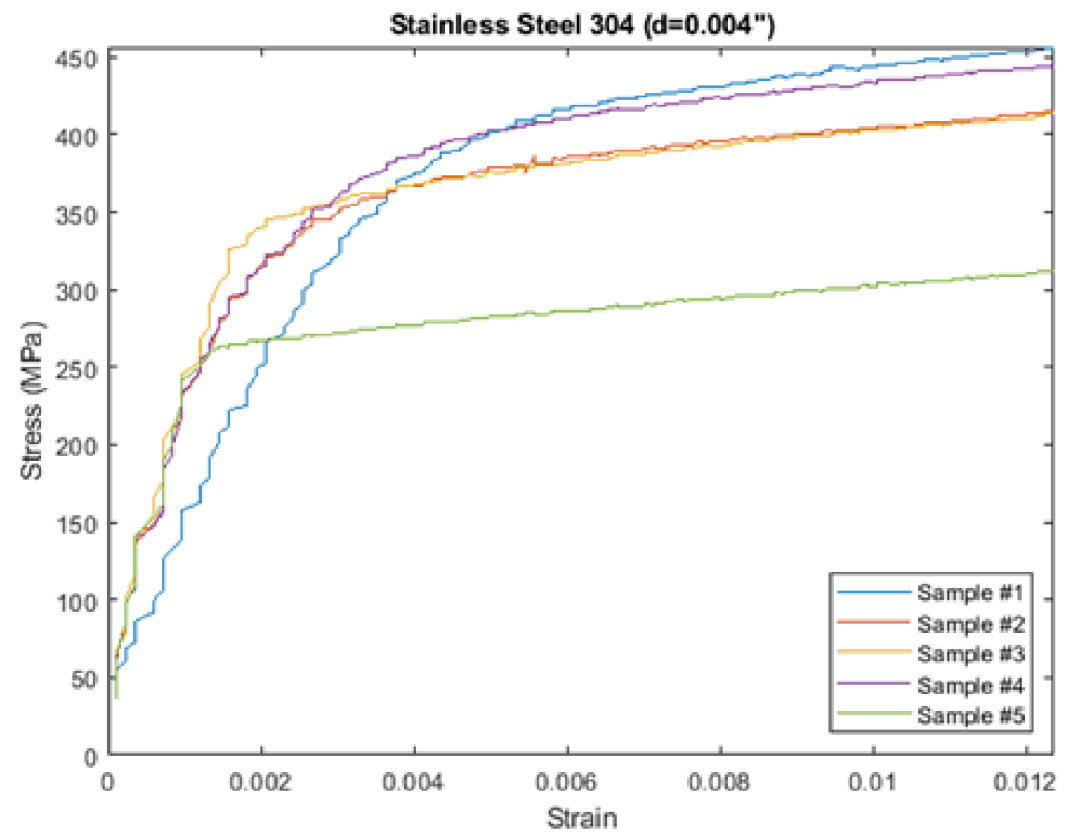

Figure 16: Stress vs. strain curves for 5 samples of stainless steel 304 wire.

Table 5 shows the modulus of elasticity for each of the 5 stainless steel samples. The average value of the modulus of elasticity for stainless steel 304 from this sample batch was $194.9 \mathrm{GPa}$. The value for the modulus of elasticity for stainless steel 304 at room temperature is $193 \mathrm{GPa}$ [12]. These results show that the thermo-mechanical test facility can replicate known mechanical property values.

Table 5: Experimental modulus of elasticity values from stainless steel 304 wire samples. 


\begin{tabular}{|c|c|}
\hline Sample \# & $\begin{array}{c}\text { Modulus of Elasticity } \\
\text { (GPa) }\end{array}$ \\
\hline 1 & 156.1 \\
\hline 2 & 205.2 \\
\hline 3 & 216.5 \\
\hline 4 & 205.1 \\
\hline 5 & 191.4 \\
\hline Average & $\mathbf{1 9 4 . 9}$ \\
\hline
\end{tabular}

\subsubsection{Optical Fiber Tensile Testing}

The optical fiber samples tested can be seen below in Table 6, these fibers are the same as the samples tested for transmission at various temperatures, including one addition specialty fiber. The gauge length for all of the samples was $927 \mathrm{~mm}$ and the nominal strain rate was 3\%. All of the fiber types were tested at room temperature and for the fiber types with multiple samples testing was completed at elevated temperatures of $100^{\circ} \mathrm{C}$ and $200^{\circ} \mathrm{C}$.

Table 6: Optical fiber samples tested in the thermo-mechanical test facility. (*Fiber fractured at capstan)

\begin{tabular}{|l|l|l|c|c|c|c|}
\hline \multicolumn{1}{|c|}{ Fiber } & Company & Coating Type & $\begin{array}{c}\text { Temperature } \\
\left({ }^{\circ} \mathbf{C}\right)\end{array}$ & $\begin{array}{c}\text { Cladding } \\
\text { Diameter }\end{array}$ & $\begin{array}{c}\text { Coating } \\
\text { Diamete } \\
\text { r }\end{array}$ & $\begin{array}{c}\text { Failure } \\
\text { Tension (N) }\end{array}$ \\
\hline B-Ge-doped & Newport & Dual Acrylate & Room & 125 & 245 & 65 \\
\hline B-Ge-doped & Newport & Dual Acrylate & 100 & 125 & 245 & 64.5 \\
\hline Nd-doped & Newport & Dual Acrylate & Room & 125 & 245 & 58 \\
\hline Yt-doped & Newport & Dual Acrylate & Room & 235 & 350 & 145 \\
\hline Ge-doped & Corning & Dual Acrylate & Room & 125 & 245 & 60 \\
\hline Ge-doped & Corning & Dual Acrylate & 100 & 125 & 245 & 59 \\
\hline Ge-doped & Corning & Dual Acrylate & 200 & 125 & 245 & 66 \\
\hline Ge-doped & Thorlabs & Dual Acrylate & Room & 125 & 245 & 66.5 \\
\hline Ge-doped & Thorlabs & Dual Acrylate & 100 & 125 & 245 & 63 \\
\hline Ge-doped & Thorlabs & Dual Acrylate & 200 & 125 & 245 & 66.5 \\
\hline Er-doped* & Thorlabs & Dual Acrylate & Room & 125 & 245 & 43.5 \\
\hline Er-doped & Thorlabs & Dual Acrylate & 200 & 125 & 245 & 55 \\
\hline F-doped & Polymicro & Acrylate & Room & 220 & 500 & 111.5 \\
\hline F-doped & Polymicro & Acrylate & 100 & 220 & 500 & 118.5 \\
\hline F-doped & Polymicro & Acrylate & 200 & 220 & 500 & 121.5 \\
\hline $\begin{array}{l}\text { F-doped } \\
(1310 \text { HTA) }\end{array}$ & Nufern & Acrylate & Room & 125 & 245 & 63.5 \\
\hline $\begin{array}{l}\text { F-doped } \\
(1310 \text { HTA })\end{array}$ & Nufern & Acrylate & 100 & 125 & 245 & 64.5 \\
\hline $\begin{array}{l}\text { F-doped } \\
(1310 \text { HTA })\end{array}$ & Nufern & Acrylate & 200 & 125 & 245 & 65.5 \\
\hline $\begin{array}{l}\text { F-doped } \\
(1550 \text { HTA) }\end{array}$ & Nufern & Acrylate & Room & 125 & 245 & 62.5 \\
\hline $\begin{array}{l}\text { F-doped } \\
(1550 \text { HTA) }\end{array}$ & Nufern & Acrylate & 100 & 125 & 245 & 62.5 \\
\hline $\begin{array}{l}\text { F-doped } \\
(1550 \text { HTA) }\end{array}$ & Nufern & Acrylate & 200 & 125 & 245 & 64.5 \\
\hline
\end{tabular}


The force $(\mathrm{N})$ over distance $(\mathrm{mm})$ data was used to calculate the stress-strain curves for each of the fiber samples at temperatures from room temperature up to $200^{\circ} \mathrm{C}$. The stress $(\sigma)$ was calculated according to the standard TIA-455-28-C, using Equation 3.

Where $(\mu \mathrm{m})$ is the diameter of the fiber coating and is the tension $(\mathrm{N})$. This method of stress

calculation does not compensate for the coating. Most in-pile applications of optical fibers will leave the coating intact upon initial fabrication and insertion of the sensors.

\subsubsection{Germanium Doped Optical Fibers}

Two types of germanium doped optical fiber was tested at room temperature, $100^{\circ} \mathrm{C}$, and $200^{\circ} \mathrm{C}$. Figure 17 and Figure 18 show the stress-strain curves for both the Corning and Thorlabs Ge doped optical fiber. There is no significant difference in the failure stress of either fiber at any of the temperatures. For the purpose of deployment as sensors the dynamic strength of both of the fibers is not significantly affected by temperatures up to $200^{\circ} \mathrm{C}$ or the slight differences in the germanium concentrations between the fibers.

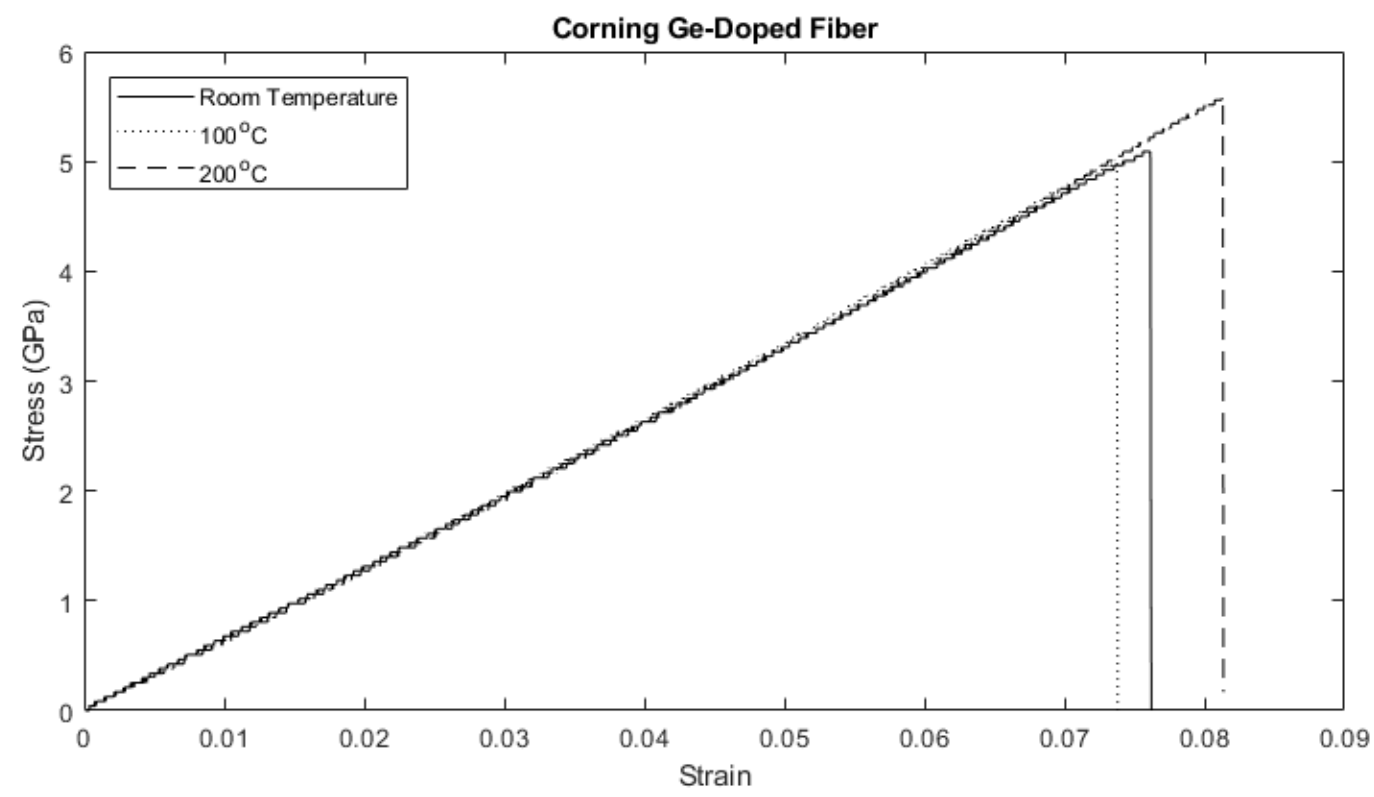

Figure 17: Stress-strain curve for germanium doped clad Corning optical fiber. 


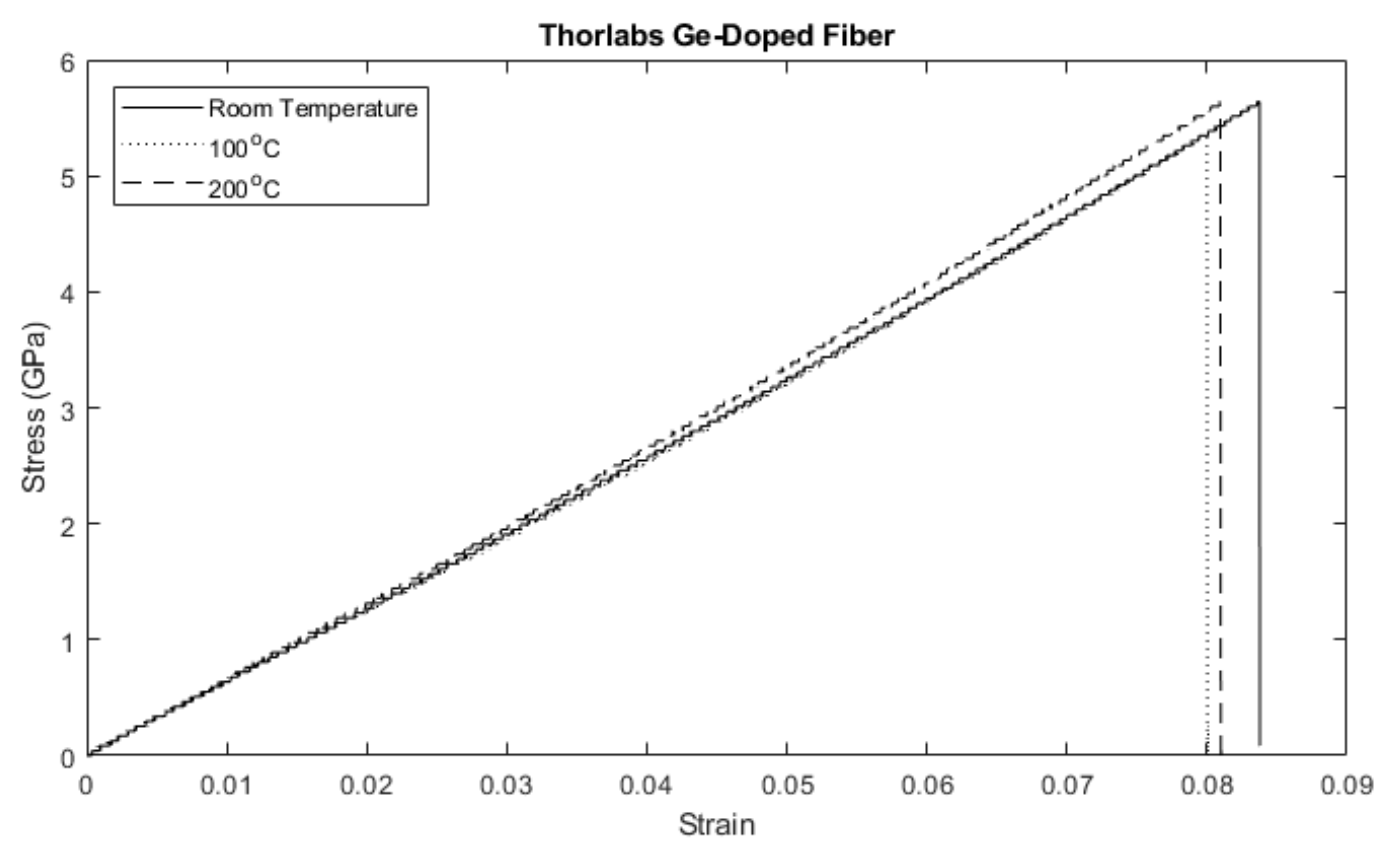

Figure 18: Stress-strain curve for germanium doped clad Thorlabs optical fiber.

\subsubsection{Pure Silica Core Optical Fibers}

PSC optical fibers are appealing for the radiation resistant that has been reported in literature [8,9]. Three types of fibers from two vendors were tested to evaluate the changes in dynamic fiber strength with temperature. Figure 19 and Figure 20 show the stress-strain curves of PSC fluorine doped clad Nufern fibers, one designed for transmission at $1310 \mathrm{~nm}$ and the other for transmission at $1550 \mathrm{~nm}$ for temperatures from room temperature up to $200^{\circ} \mathrm{C}$. Figure 21 shows the same response for Polymicro PSC, fluorine doped clad fiber.

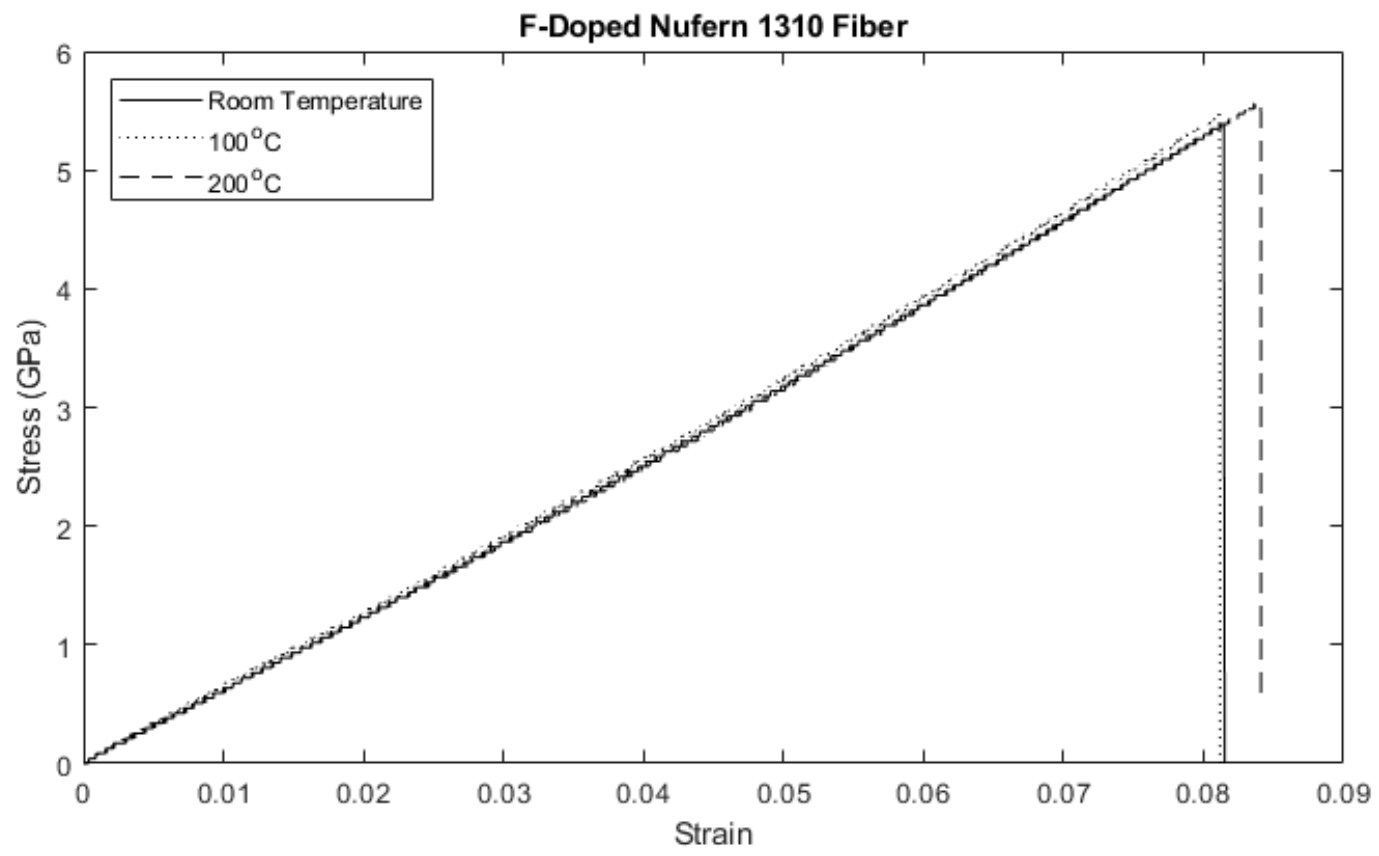

Figure 19: Stress-strain curve for pure silica core, fluorine doped clad Nufern 1310 optical fiber. 


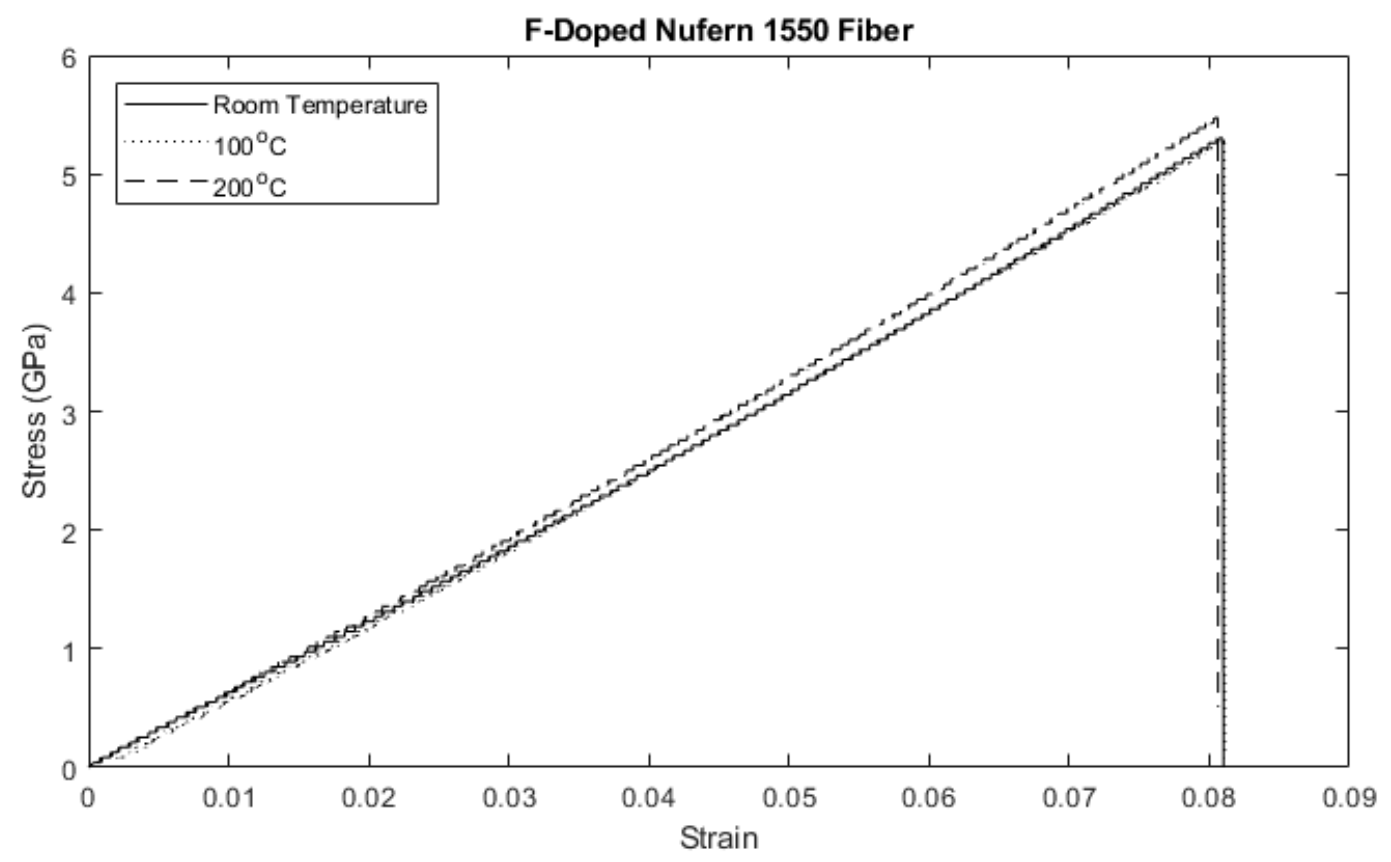

Figure 20: Stress-strain curve for pure silica core, fluorine doped clad Nufern 1550 optical fiber.

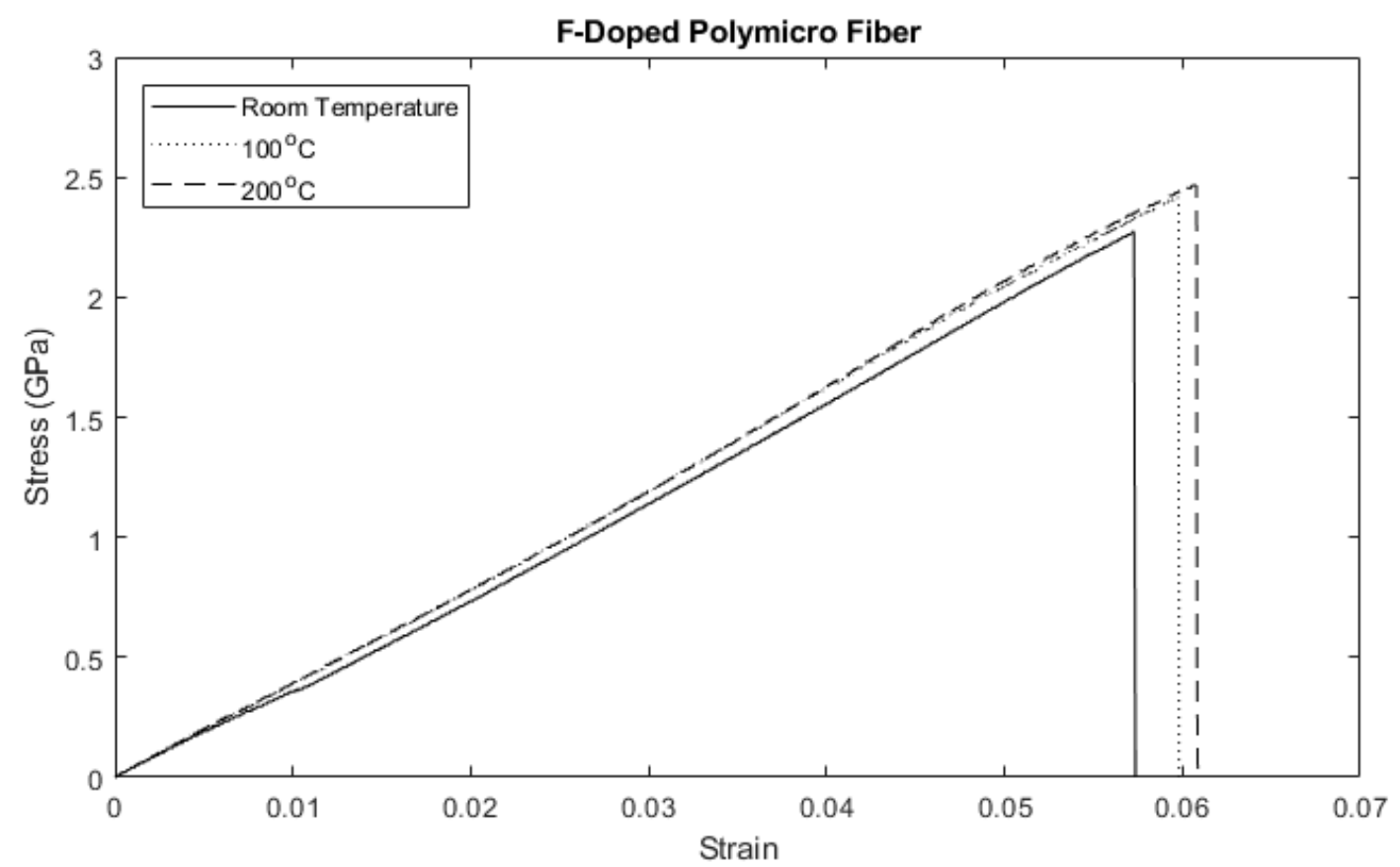

Figure 21: Stress-strain curve for pure silica core, fluorine doped clad Polymicro optical fiber.

It should be noted that the coating diameter of the Polymicro fiber was twice the coating diameter of the Nufern fiber, the clad diameter of the Polymicro fiber was also larger than that of the Nufern fiber. While the diameter of the coating is used in the calculation of the stress-strain curve it does appear to have affected the stress-strain relationship of the Polymicro fiber. There is no noticeable difference in the strength of the two Nufern fibers or at elevated temperatures. The Polymicro fiber failed at a stress about half that of the Nufern fibers and temperature does appear to allow the fiber to elongate more as temperature rises. This may be due to softening of the coating with temperature allowing the fiber to 
stretch more before fracturing.

\subsubsection{Specialty Optical Fiber}

Four specialty fibers were chosen for potential sensor applications and for the use of the fibers within laser systems rather than just harsh environment tolerance. A boron and germanium co-doped optical fiber, an erbium doped optical fiber, a yttrium doped fiber, and a neodymium doped optical fiber were all tested for tensile strength.

\subsubsection{Boron and Germanium Co-doped Optical Fiber}

As mentioned previously, boron has a large neutron cross section making it very sensitive to neutron flux. A boron and germanium co-doped optical fiber was tested in the thermos-mechanical test facility and the stress-strain curve can be seen in Figure 22. The B-Ge co-doped optical fiber performed similarly to the standard germanium doped optical fibers.

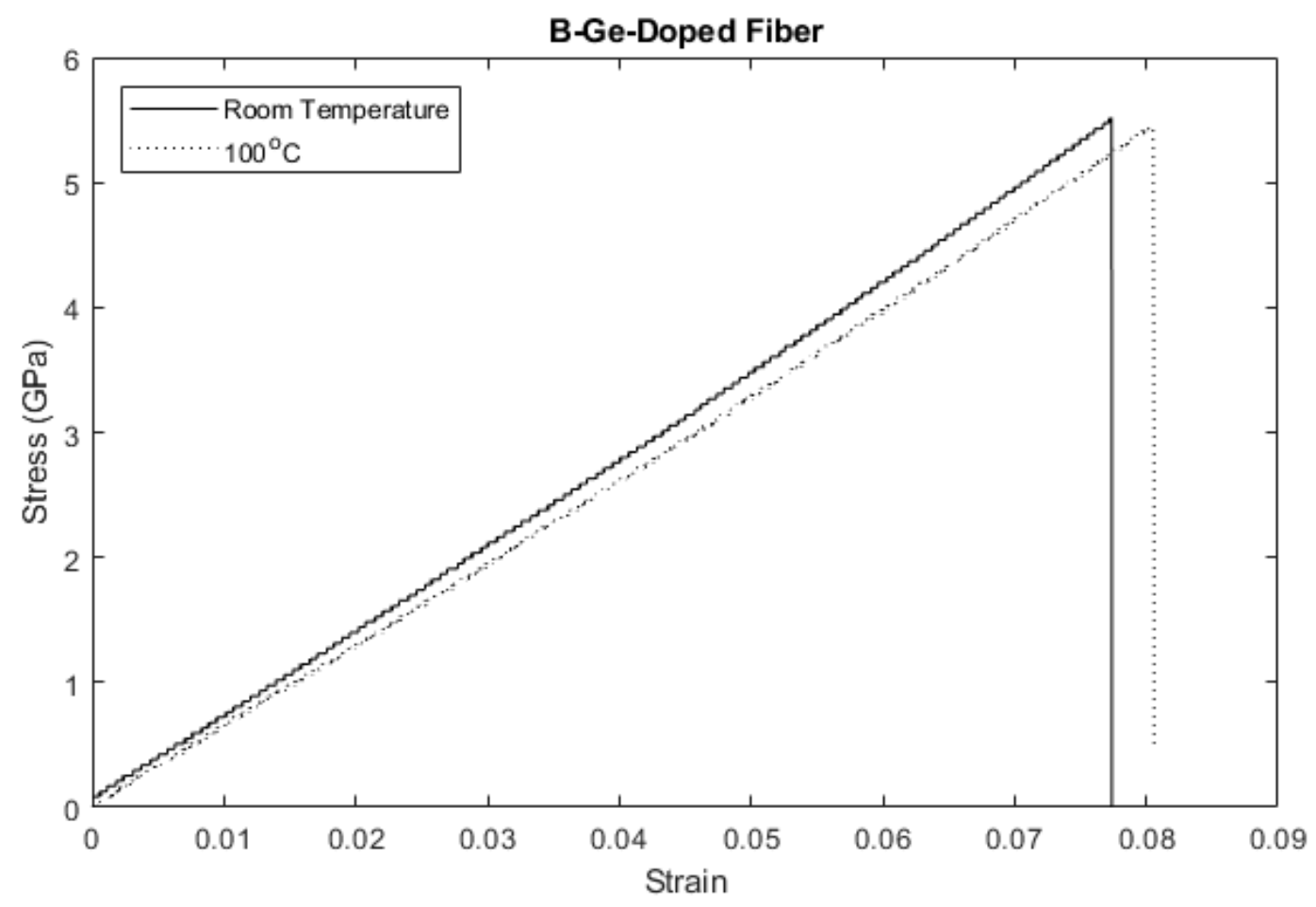

Figure 22: Stress-strain curve for boron and germanium co-doped optical fiber.

\subsubsection{Erbium Doped, Neodymium Doped, and Yttrium Doped Optical Fibers}

Erbium, neodymium, and yttrium doped optical fibers are all used in laser systems and could be potentially useful for deployment in in-pile experiments. The room temperature pull of the Er doped fiber broke at the capstan and that stress-strain curve is considered unreliable. The Er doped fiber at $200^{\circ} \mathrm{C}$ fractured at a slightly lower stress than the standard Ge doped optical fibers, the stress-strain curve is show in Figure 23. 


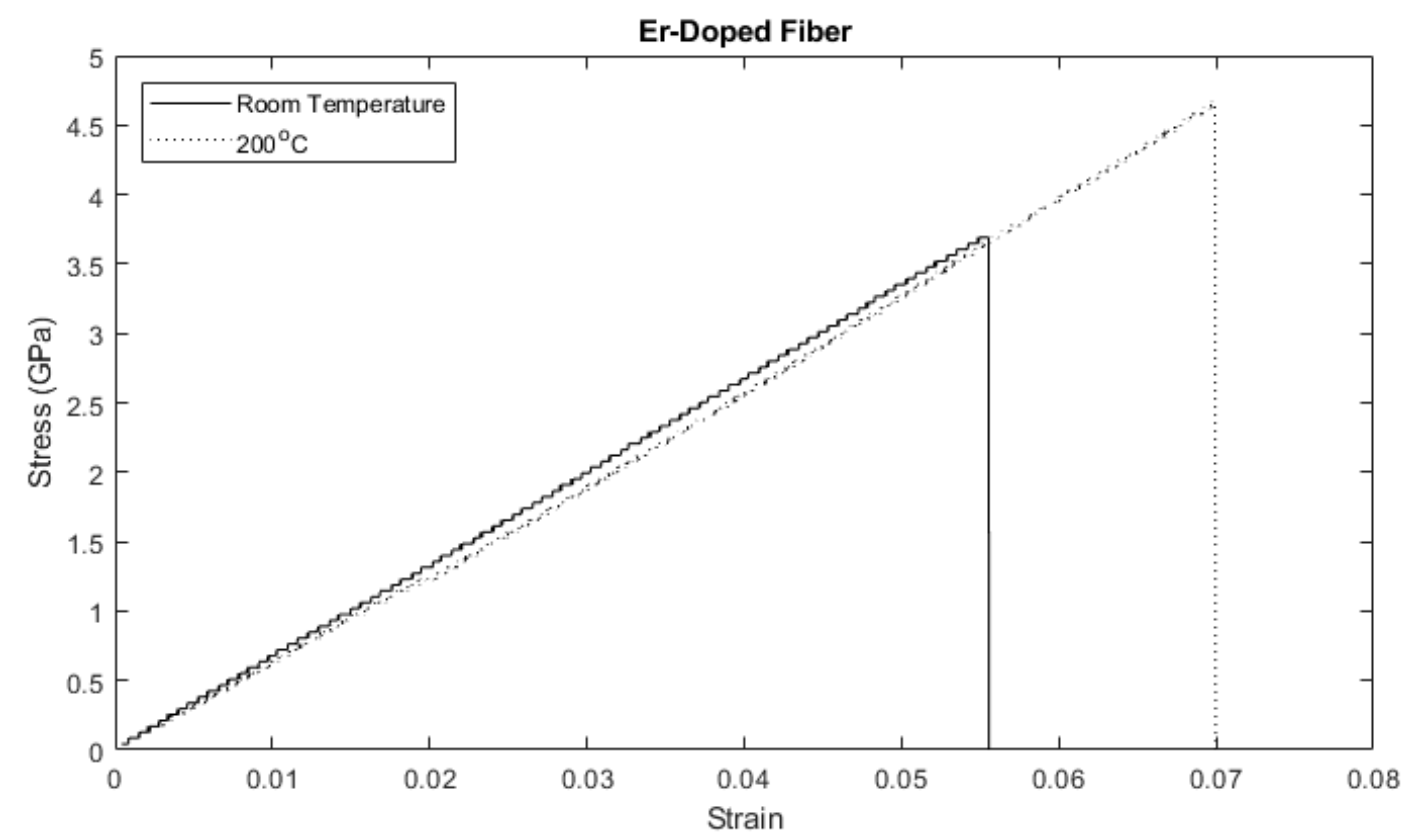

Figure 23: Stress-strain curve for erbium doped optical fibers. Note: The room temperature test sample broke at the capstan.

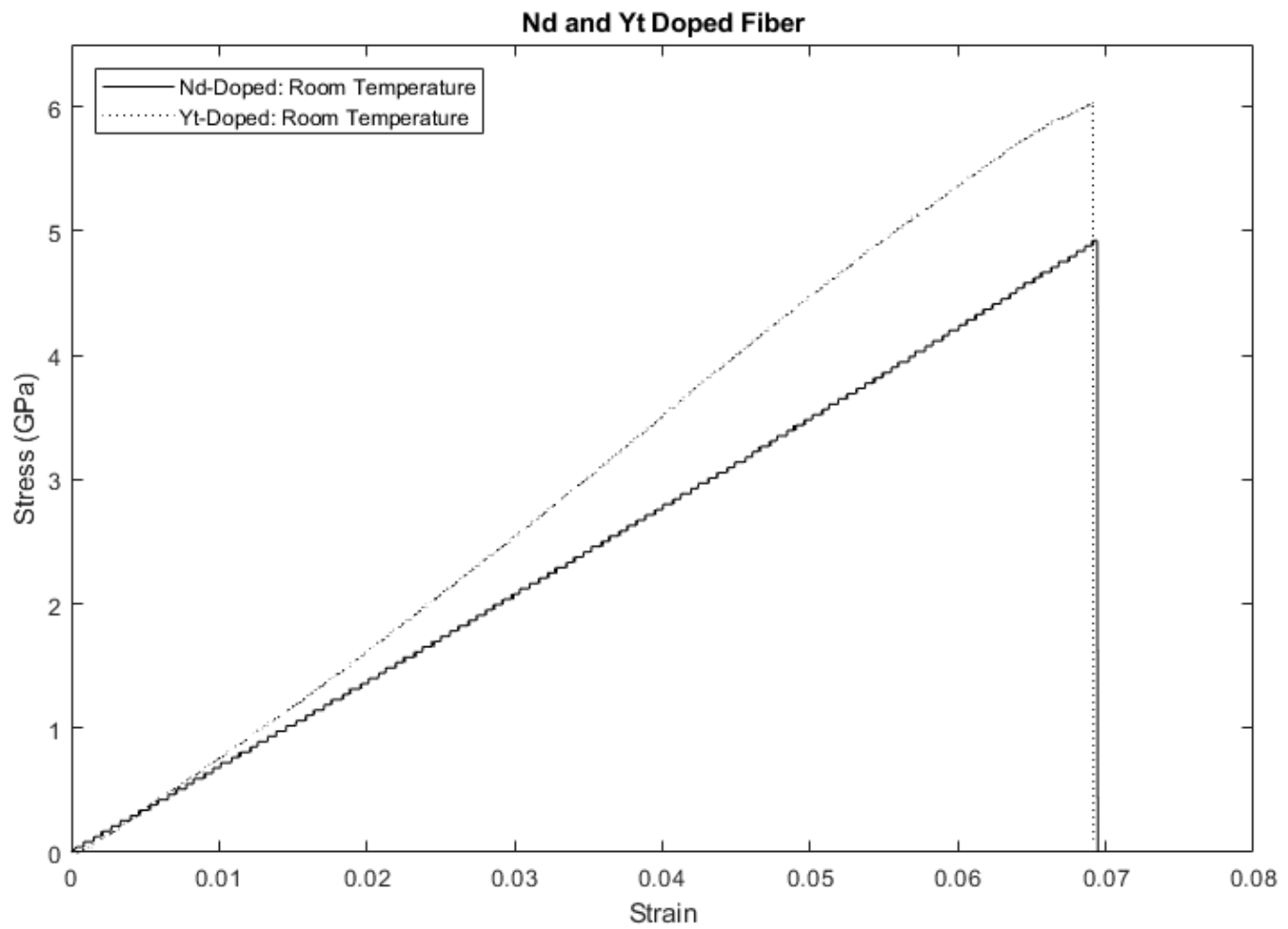

Figure 24: Stress-strain curve for Neodymium and Yttrium doped optical fibers.

Figure 24 shows the stress-strain curves for the $\mathrm{Nd}$ doped and $\mathrm{Yt}$ doped optical fibers at room temperature. The Yt doped fiber broke at a higher stress than the Nd fiber but almost the same strain. 
This reasonable because the coating diameter of the Yt doped fiber is larger than that of the Nd doped fiber, the larger diameter coating would require more force to elongate the fibers the same amount.

\subsubsection{Discussion}

Tensile testing of optical fibers sensors showed that temperatures up to $200^{\circ} \mathrm{C}$ have little effect on the dynamic strength of various types of optical fibers. Most of the fibers tested had $245 \mu \mathrm{m}$ diameter coatings, these fibers all fractured around the same stress. The larger diameter coated fibers fractured at lower stresses and strains than the smaller diameter counterparts. The Polymicro PSC fluorine doped clad optical fiber broke at the lowest stress and strain, this fiber also had the largest diameter coating at 500 $\mu \mathrm{m}$. The rare-earth mineral doped optical fibers, Er doped, Nd doped, and Yt doped, broke at the lowest stresses and strains of the $245 \mu \mathrm{m}$ coated fibers.

\section{Summary \& Conclusion}

Out-of-pile testing of fiber optic performance has begun at both the FLaIR lab at Boise State University and at the FOUT lab at Idaho National Laboratory. The efforts detailed in this report include the temperature dependent transmission of a large variety of optical fibers, and the thermo-mechanical testing of optical fibers. Both of these test facilities have been designed, built, and commenced testing under the FY19 funding.

The fiber optic transmission testing facility has the capability to test the transmission of optical fibers over a range of wavelengths and temperature. This facility was established to determine the impact temperature has on the optical performance for a variety of optical fibers. A detailed understanding of the impact the environmental conditions has on fiber optic transmission is necessary to distinguish it from the impact of radiation induced effects. The results from the fiber optic transmission testing demonstrate the wide range of capability the facility has with an emphasis on the high spectral resolution. A variety of optical fibers have been tested, ranging from standard germanium doped fibers to specialty fibers that are used only for unique applications.

The thermo-mechanical test facility has been designed, fabricated, validated, and used to test the mechanical strength of a variety of optical fibers. This test stand utilizes a Mark-10 ESM303 tensile tester and a Carbolite Gero tube furnace. The thermo-mechanical test facility enables tensile testing of specimens from room temperature up to $1200^{\circ} \mathrm{C}$. The test setup was validated by tensile testing stainless steel 304 wire, calculating the measured modulus of elasticity and comparing the measured value to those found in literature. Good agreement was found between the literature and measured value for the stainless steel 304 sample. This capability has been established to enable quantitative testing of the durability and performance of fiber optic sensors. The fragile nature of optical fiber can limit the scenarios it can be deployed. Furthermore, certain intrinsic fiber optic sensors, such as Fiber Bragg Gratings (FBGs) reduce the mechanical strength of the fiber. This test stand enables this reduction in mechanical performance to be quantified over a range of feasible deployment temperatures. Many fiber optic based strain sensors are highly influenced by the fiber temperature. This test facility is designed such that strain could be measured at a variety of temperatures to evaluate the sensitivity of the strain gauge to temperature effects. Similar to the transmission testing, a wide range of fiber optic samples have been tested in the thermomechanical test facility. These results provide a baseline in which other fibers with treatments will be compared to.

The results provided in this report demonstrate the ongoing out-of-pile testing conducted by INL and BSU in an effort to design and optimize fiber optic sensors for in-pile measurements. Pure silica core (PSC) optical fibers have been reported in literature to perform well in harsh environments. Transmission testing and tensile testing showed little change in fiber dynamic strength and transmission with elevated temperatures. There was no significant weakening of the fiber for temperatures up to $200^{\circ} \mathrm{C}$. Transmission 
at $1550 \mathrm{~nm}$ (a common wavelength used for optical sensors) showed minimal changes up to $800^{\circ} \mathrm{C}$ with some improvement after 12 hours of annealing at $800^{\circ} \mathrm{C}$. This indicates that PSC optical fiber is a good candidate for future in-pile testing.

\section{References}

1. TIA-455-28-C, Telecommunications Industry Association Standard, Measuring Dynamic Strength and Fatigue Parameters of Optical Fibers by Tension, May 10, 2005.

2. W. F. Yeung, and A. R. Johnston, "Effect of temperature on optical fiber transmission," $\square$ Applied optics, $\square$ 17, pp. 3703-3705 (1978).

3. Melanie N. Ott, "Radiation Effects Data on Commercially Available Optical Fiber: Database Summary", Radiation report for Polymicro Technologies, prepared and conducted by SEA Inc. and the Boeing Radiation Effects Lab.

4. S. Girard, J. Kuhnhenn, A. Gusarov, B. Brichard, M. V. Uffelen, Y. Ouerdane, A. Boukenter, and C. Marcandella, "Radiation effects on silica-based optical fibers: Recent advances and future challenges," IEEE Transactions on Nuclear Science, $\square$ 60, pp. 2015-2036 (2013).

5. Huang et al.,"Research of radiation resistant Er doped fiber for space detection," In $\square$ Selected Papers of the Chinese Society for Optical Engineering Conferences held July 2016, 10141, p. 1014108. International Society for Optics and Photonics, 2016.

6. Fox et al., "Gamma radiation effects in Yb-doped optical fiber." In $\square$ Fiber Lasers IV: Technology, Systems, and Applications, 6453, 645328. International Society for Optics and Photonics, 2007.

7. Pinsard et al., "Radiation-Hardened Co-Doped Optical Fiber for High-Power $1.5 \mu \mathrm{m}$ Amplifier," In $\square$ Workshop on Specialty Optical Fibers and their Applications, pp. WT4A-17. Optical Society of America, 2015.

8. Griscom et al., "Radiation hardening of pure-silica-core optical fibers: Reduction of induced absorption bands associated with self-trapped holes," $\square$ Applied physics letters $\square 71,175-177$, (1997)

9. K. Sanada, N. Shamoto, and K. Inada, "Radiation resistance of fluorine-doped silica core fibers," J. Non-Cryst. Solids 179, 339-344 (1994).

10. G. Kresse, J. Furthmüller, Efficient iterative schemes for ab initio total-energy calculations using a plane-wave basis set, Phys. Rev. B 54 (1996)11169-11186, https://doi.org/10.1103/PhysRevB.54.11169.

11. J.P. Perdew, K. Burke, M. Ernzerhof, Gen. Gradient Aprox. Made Simple 77(1996) 3865-3868, https://doi.org/10.1103/PhysRevLett.77.3865

12. Bauccio, Michael, Asm Metals Reference Book, Materials Park, Ohio: ASM International, 1993. 